\title{
Modular Functions Arising From Some Finite Groups
}

\author{
By Larissa Queen
}

\begin{abstract}
In [2] Conway and Norton have assigned a "Thompson series" of the form

$$
q^{-1}+H_{1} q+H_{2} q^{2}+\ldots
$$

to each element $m$ of the Fischer-Griess "Monster" group $M$ and conjectured that these functions are Hauptmoduls for certain genus-zero modular groups. We have found, for a large number of values of $N$, all the genus-zero groups between $\Gamma_{0}(N)$ and $P S L(2, R)$ that have Hauptmoduls of the above form, and this provides the necessary verification that the series assigned in [2] to particular elements of $M$ really are such Hauptmoduls. (Atkin and Fong [1] have recently verified that $H_{n}(m)$ really is a character of $M$ for all $n$.) We compute Thompson series for various finite groups and discuss the differences between these groups and $M$. We find that the resulting Thompson series are all Hauptmoduls for suitable genus-zero subgroups of $P S L(2, R)$.
\end{abstract}

1. Summary. Some remarkable connections between the Fischer-Griess "Monster" group $M$ and modular functions have recently been reported in [2] and [5]. It has been noticed that the coefficients in the $q$-series for $j$

$$
j(z)=\sum_{n=-1}^{\infty} c_{n} q^{n}=q^{-1}+744+196884 q+21493760 q^{2}+\ldots,
$$

where $j$ is the fundamental modular function on $\Gamma=\operatorname{PSL}(2, Z)$ and $q=e^{2 \pi i z}$, are linear combinations of the character degrees $d_{n}$ of $M$. By considering $J=j-744$, i.e., disregarding the constant term, and replacing the coefficients $c_{n}$ in the $q$-series for $J$ by the corresponding representations of $M$, one obtains a formal power series [5]

$$
\mathrm{H}_{-1} q^{-1}+\mathrm{O}+\mathrm{H}_{1} q+\mathrm{H}_{2} q^{2}+\mathrm{H}_{3} q^{3}+\ldots
$$

where $q=e^{2 \pi i z}$ and $H_{n}$ is a representation of degree $c_{n}$ known as a head representation. Replacing $H_{n}$ by its character value $H_{n}(m)$ for various elements $m \in M$, we obtain other functions [5]:

$$
T_{m}(z)=q^{-1}+H_{1}(m) q+H_{2}(m) q^{2}+H_{3}(m) q^{3}+\ldots,
$$

which are called the Thompson series in [2]. The $H_{i}(m)$ are called head characters. Conway and Norton [2] have computed the functions $T_{m}(z)$ for all elements $m$ of $M$, and they conjectured that, for every $m \in M, T_{m}(z)$ is a Hauptmodul for a group $F(m)$ between $\Gamma_{0}(N)$ for some $N$ and its normalizer in $P S L(2, R)$, i.e., $T_{m}(z)$ generates a genus-zero function field invariant under $F(m)$. In this paper we describe certain related calculations. The detailed working can be found in [4]. We have explicitly verified that the modular functions assigned to various $m$ by

Received June 16, 1980.

1980 Mathematics Subject Classification. Primary 20C15, 10D05. 
Conway and Norton [2] are actually Hauptmoduls for the groups they mention. Atkin and Fong [1] have recently verified that $H_{n}(m)$ really is a character of $M$ for all $n$.

We have also considered other finite groups, usually derived from centralizers of elements of $M$, and computed their head character tables. In particular, we consider

$\begin{array}{ll}.0=2 .(.1) & .1 \text { is the Conway simple group } \\ E & \text { Thompson's simple group } \\ \text { 3.2.Suz } & \text { Suz is Suzuki's sporadic simple group } \\ \text { 2.HJ } & \text { HJ is the Hall-Janko simple group } \\ F & \text { Harada-Norton simple group } \\ 2 . A_{7} & \text { Schur double cover of } A_{7} \\ H & \text { Held's simple group } \\ M_{12} & \text { Mathieu simple group }\end{array}$

for which we have

$\begin{array}{ccl}\text { elements of } M & \text { centralizer in } M & \\ 2 B & 2^{1+24} \cdot G & G=.1 \\ 3 B & 3^{1+12} \cdot G & G=2 . \mathrm{Suz} \\ 3 C & 3 \times E & \\ 5 A & 5 \times F & \\ 5 B & 5^{1+6} \cdot G & G=2 . \mathrm{HJ} \\ 7 A & 7 \times H & \\ 7 B & 7^{1+4} \cdot G & G=2 . A_{7} \\ 11 A & 11 \times M_{12} & \end{array}$

2. Notation and Terminology. As usual, for a positive integer $N$, we define

$$
\Gamma(N)=\left\{\left(\begin{array}{ll}
a & b \\
c & d
\end{array}\right) \in \Gamma: a \equiv d \equiv 1(\bmod N), b \equiv c \equiv 0(\bmod N)\right\}
$$

and

$$
\Gamma_{0}(N)=\left\{\left(\begin{array}{ll}
a & b \\
c & d
\end{array}\right) \in \Gamma: c \equiv 0(\bmod N)\right\}
$$

We also define

$$
\Gamma_{0}(n: h)=\left\{\left(\begin{array}{cc}
a & b / h \\
c n h & d
\end{array}\right): a d-b c n=1\right\},
$$

which is a subgroup of $\operatorname{PSL}(2, R)$ and is conjugate to $\Gamma_{0}(n)$. In [2] this group is denoted by $\Gamma_{0}(n h \mid h)$; however, we prefer to reserve this name to denote a subgroup of $\Gamma_{0}(n: h)$ of index $h$ which has Hauptmodul $T_{n h \mid h}$ (see below). Thus, adapting the rest of the notation from [2], we always have the same name for the genus-zero subgroup of $P S L(2, R)$ and the corresponding Hauptmodul in the canonical form (i.e. beginning $q^{-1}+0+a q+\ldots$ ). Also, this notation provides a natural way of enumerating all discrete subgroups of $\operatorname{PSL}(2, R)$ containing $\Gamma_{0}(N)$ for a given $N$; see [4]. 
Thus, we write

$$
\begin{array}{ll}
\Gamma_{0}(n: h)+e, f, \ldots & \text { for }\left\langle\Gamma_{0}(n: h), w_{e}, w_{f}, \ldots\right\rangle, \\
\Gamma_{0}(n: h)+ & \text { when all } w_{e} \text { for } \Gamma_{0}(n: h) \text { are present, } \\
\Gamma_{0}(n: h)-\text { or } \Gamma_{0}(n: h) & \text { when no } w_{e} \neq 1 \text { is present, }
\end{array}
$$

where

$$
w_{e}=\left\{\left(\begin{array}{cc}
a e & b / h \\
c h n & d e
\end{array}\right): e \text { divides } n \text { exactly, and } a d e^{2}-b c n=e>0\right\}
$$

is a single coset of $\Gamma_{0}(n: h)$. The $w_{e}$ are called the Atkin-Lehner involutions for $\Gamma_{0}(n: h)$ [2]. The corresponding Hauptmoduls (when they exist) are denoted by $t_{n+e, f, \ldots}(h z), t_{n+}(h z)$ and $t_{n-}(h z)$ or $t_{n}(h z)$, respectively. $\Gamma_{0}(n)$ and its Hauptmodul $t_{n}(z)$ are a particular case when $h=1$.

$$
T_{n+e f, \ldots}(h z)=t_{n+e, f, \ldots}(h z)-\text { constant term }
$$

is the canonical Hauptmodul for $\Gamma_{0}(n: h)+e, f, \ldots$

If $F$ is a subgroup of $\Gamma_{0}(n: h)+e, f, \ldots$ of index $h$, with Hauptmodul $T$ and $(T(z))^{h}=T_{n}(h z)+K$, where $K$ is a constant, we denote $F$ by $\Gamma_{0}(n h \mid h)+$ $e, f, \ldots$ and $T$ by $T_{n h \mid h+e, f, \ldots}$.

In this work we also define

$$
\begin{aligned}
\Gamma_{0}\left(n \frac{f}{g}\right) & =\left(\begin{array}{ll}
g & f \\
0 & g
\end{array}\right) \Gamma_{0}(n)\left(\begin{array}{cc}
g & -f \\
0 & g
\end{array}\right), \\
\Gamma_{0}\left(n \frac{f}{g}\right)+ & =\left(\begin{array}{ll}
g & f \\
0 & g
\end{array}\right) \Gamma_{0}(n)+\left(\begin{array}{cc}
g & -f \\
0 & g
\end{array}\right), \\
\Gamma_{0}\left(n \frac{f}{g} h: h\right)+ & =\left(\begin{array}{ll}
1 & 0 \\
0 & h
\end{array}\right) \Gamma_{0}\left(n \frac{f}{g}\right)+\left(\begin{array}{ll}
h & 0 \\
0 & 1
\end{array}\right),
\end{aligned}
$$

where $g$ is such that $g \mid 24$ and $(g, f)=1$. The corresponding functions are

$$
t_{n(f / g)}(z)=e^{2 \pi i f / g} t_{n}(z+f / g), \quad t_{n(f / g)+}(z)=e^{2 \pi i f / 8} t_{n+}(z+f / g),
$$

and $t_{n(f / g)+}(h z)$, respectively. These are used to label a wide class of groups and functions arising from various finite groups $G$ considered in this paper.

From [2] we quote certain identities which are called there replication formulae:

$$
\begin{aligned}
\frac{1}{2}\left\{T^{2}-T_{(2)}(2 z)\right\}= & \left\{H_{2} q+H_{4} q^{2}+\ldots\right\}+H_{1} \quad \text { (duplication), } \\
\frac{1}{3}\left\{T^{3}-T_{(3)}(3 z)\right\}= & \left\{H_{3} q+H_{6} q^{2}+\ldots\right\}+H_{1} T+H_{2} \text { (triplication), } \\
\frac{1}{5}\left\{T^{5}-T_{(5)}(5 z)\right\}= & \left\{H_{5} q+H_{10} q^{2}+\ldots\right\}+H_{1} T^{3}+H_{2} T^{2} \\
& +\left(H_{3}-H_{1}^{2}\right) T+\left(H_{4}-H_{2} H_{1}\right)
\end{aligned}
$$

where $T=T_{m}(z), T_{(n)}=T_{m^{n}}$ and $H_{r}=H_{r}(m)$, for $m \in M$. Many identities are obtained by comparing powers of $q$.

3. Discussion of Calculations and Results. When computing their Thompson series, the groups mentioned above fall naturally into two classes. The first one consists of $G_{2}=.0, G_{3}=3.2 . \mathrm{Suz}, G_{5}=2 . \mathrm{HJ}$ and $G_{7}=2 . A_{7}$. Each of these groups has a central element -1 and two algebraically conjugate representations $\left[d_{+}\right]$and [ $d_{-}$] of degree $d=24 /(p-1)$, where $p$ is the order of the element of $M$ whose 
centralizer involves $G_{p}$ for $p=2,3,5,7$. If $G$ is one of these groups, then for every $g \in G$ the Thompson series $t_{g}$ is given by the formula

$$
\begin{aligned}
t_{g}(z) & =q^{-1} \prod_{p \nmid n}\left(1-\varepsilon_{1} q^{n}\right)\left(1-\varepsilon_{2} q^{n}\right) \cdots\left(1-\varepsilon_{d} q^{n}\right) \\
& =q^{-1}+H_{0}(g)+H_{1}(g) q+H_{2}(g) q^{2}+\ldots
\end{aligned}
$$

$\left(q=e^{2 \pi i z}\right)$, where the $\varepsilon$ 's are the eigenvalues of $g$ in the representation $\left[d_{(n / p)}\right]$, and $(n / p)$ is the Legendre symbol. The $H_{i}(g)$ is a generalized character of $G$, while it can be shown that $H_{i}(-g)$ is a proper character; see [2]. However, our calculations show that the replication order of $t_{g}$ is always less than or equal to the replication order of $t_{-g}$, and so they cannot be interchanged. We also observe that, as was not the case for $M$, the constant term is significant. In fact, $H_{0}(-g)$ is the character of $G$ corresponding to the representation $\left[d_{+}\right]$.

The second class includes $E, F, H$ and $M_{12}$. To compute the Thompson series for $g \in G$, where $G$ is one of the groups above, we have to find, by trial and error, linear combinations of irreducible characters of $G$ that work, i.e., such that the resulting Thompson series can be identified as modular functions for certain discrete subgroups of $\operatorname{PSL}(2, R)$. Of course, such linear combinations do not have to exist, and in fact it is quite amazing that they do. For these groups, $H_{i}(g)$ is a proper character of $G$ and the constant term is immaterial.

Tables I-VIII give values of head characters for these groups, together with the decomposition of the $H_{i}(g)$ into the irreducible characters of $G$. We found that to every element $g \in G$, where $G$ is one of the groups above, there corresponds a function

$$
t_{g}(z)=q^{-1}+H_{0}(g)+H_{1}(g) q+H_{2}(g) q^{2}+\ldots,
$$

which can be identified as a Hauptmodul for a discrete subgroup $F=F(g)$ of $\operatorname{PSL}(2, R)$ containing $\Gamma_{0}(N)$ for some $N$ and such that $F_{\infty}=\left\langle\left(\begin{array}{ll}1 & 1 \\ 0 & 1\end{array}\right)\right\rangle$, where $F_{\infty}$ is the stabilizer of the cusp at $z=i \infty$. However, $F(g)$ is not necessarily contained in the normalizer of $\Gamma_{0}(N)$ in $\operatorname{PSL}(2, R)$, as was the case for $M$. Tables I-VIII also include the corresponding $\Gamma_{0}(N)$ and the type $t$ (i.e., the name of the fixing group and the corresponding Hauptmodul) of $t_{g}(z)$ for every $g \in G$.

Some observations resulting from this work, in particular some necessary alterations in the replication formulae and the more general form of fixing group $F(g)$, have already been reported upon in [2].

Let $G$ be one of the groups considered above. Let $p$ be the order of the element of $M$ from whose centralizer $G$ was derived. If $(n / p)=-1, H_{n}(g)$ are rational for all $g \in G$, and the $n$-tuplication formulae are used with algebraic conjugation.

If $g \in G$ of order $s$ such that $(s, p)=1$, then its Thompson series $T_{g}$ is the same as $T_{m}$ for some $m \in M$, i.e., we can obtain new functions only from the elements of $G$ whose order is divisible by $p$.

Consider $T=T_{g}$, where $g \in M$ or $g \in G$ for one of the groups $G$ discussed above. The replication formulae [2] define a function $T_{(n)}$, called the $n$-tuplicate of $T$. If $T=T_{m}$ for $m \in M$,

$$
T_{(n)}=T_{m^{n}}
$$


For an arbitrary Thompson series $T$, we say that $T$ has replication order $n$ if

$$
T_{(n)}=J .
$$

We note that $J$ is a self-replicating function, and it assumes the role of the identity.

Let $G$ and $p$ be as above and let $T=T_{g}$ for $g \in G$. If $(n, p)=1$,

$$
T_{(n)}=T_{g^{n}}
$$

Hence, if $g \in G$ and $o(g)=s$ such that $(s, p)=1$,

$$
T_{(s)}=T_{1 A(G)} \text {, }
$$

where $1 A(G)$ is the identity element of $G$, and $T$ has replication order ps. On the other hand, if $(n, p) \neq 1$,

$$
T_{(n)}=T_{m}
$$

for some $m \in M$. For example, we found in $F$ that $T_{5 A}$ has replication order 5 , $T_{10 B}$ has replication order $10, T_{15 A}$ has replication order $15, T_{20 C}$ has replication order 20 and $T_{25 A}, T_{25 B}$ have replication order 25 , where $5 A, 10 B, 15 A, 20 C, 25 A$, and $25 B$ are elements of order $5,10,15,20$, and 25 , respectively.

We would like to note that since $G=3.2$.Suz contains a central element $\omega$ of order 3 , for every $t_{g}(z)$ given in Table II we also have

$$
t_{\omega g}(z)=\omega t_{g}(z+1 / 3)
$$

and

$$
t_{\bar{\omega} g}(z)=\bar{\omega} t_{g}(z+2 / 3)=t_{\omega g}^{*}(z),
$$

where * denotes algebraic conjugation.

In our calculations we used the character tables from [3].

Department of Pure Mathematics and Mathematical Statistics

University of Cambridge

Cambridge CB2 1SB, England

1. A. O. L. Atken \& P. Fong, A communication at the A. M. S. Conference on Finite Simple Groups, Santa Cruz, 1979.

2. J. H. Conway \& S. P. Norton, “Monstrous moonshine," Bull. London Math. Soc., v. 11, 1979, pp. 308-340.

3. J. H. Conway, R. T. Curtis, S. P. Norton \& R. A. Parker, An Atlas of Finite Groups. (In preparation.)

4. L. QUEEN, Some Relations Between Finite Groups, Lie Groups and Modular Functions, Ph.D. Dissertation, Cambridge, April 1980.

5. J. G. Thompson, "Some numerology between the Fischer-Griess monster and the elliptic modular function," Bull. London Math. Soc., v. 11, 1979, pp. 352-353. 


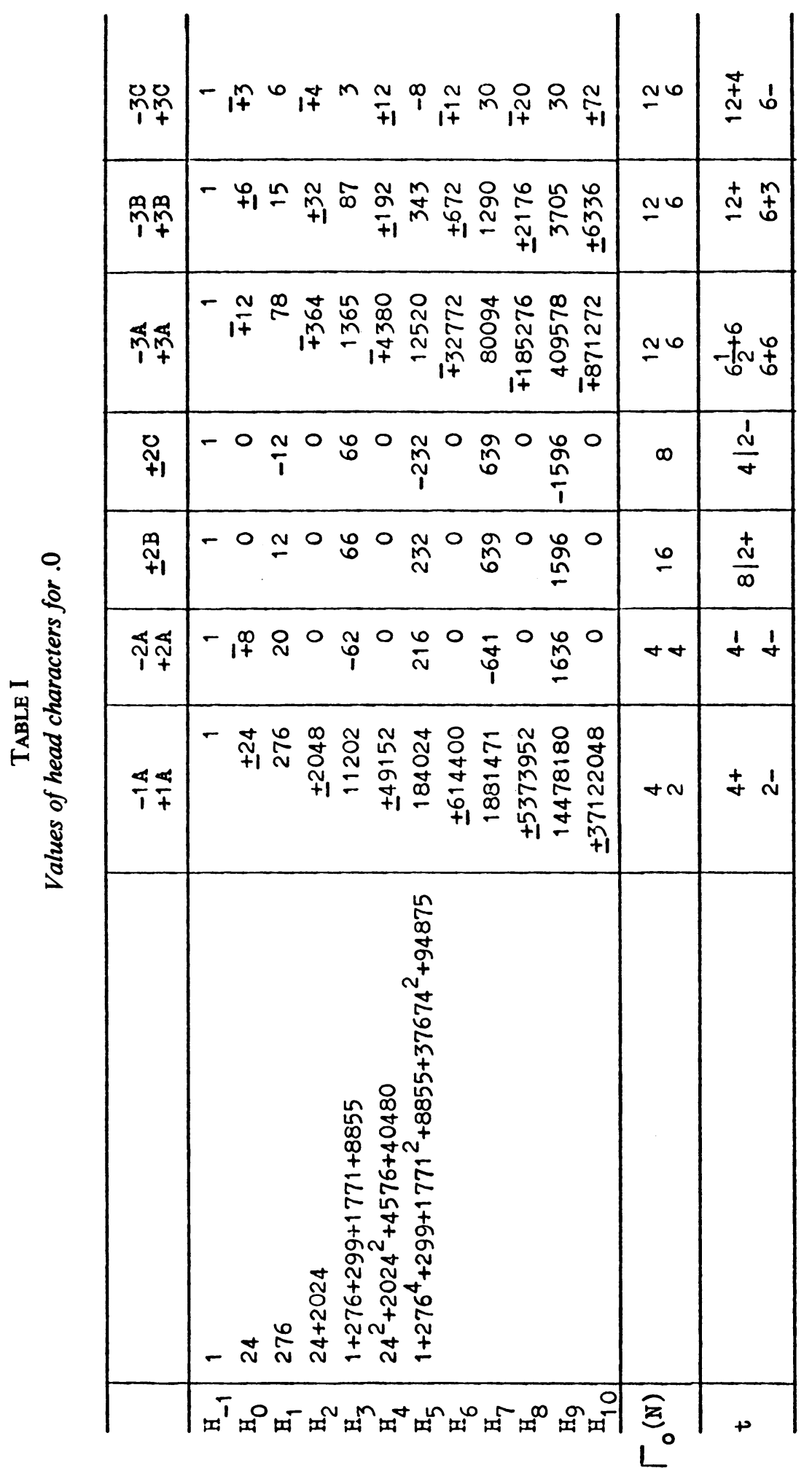




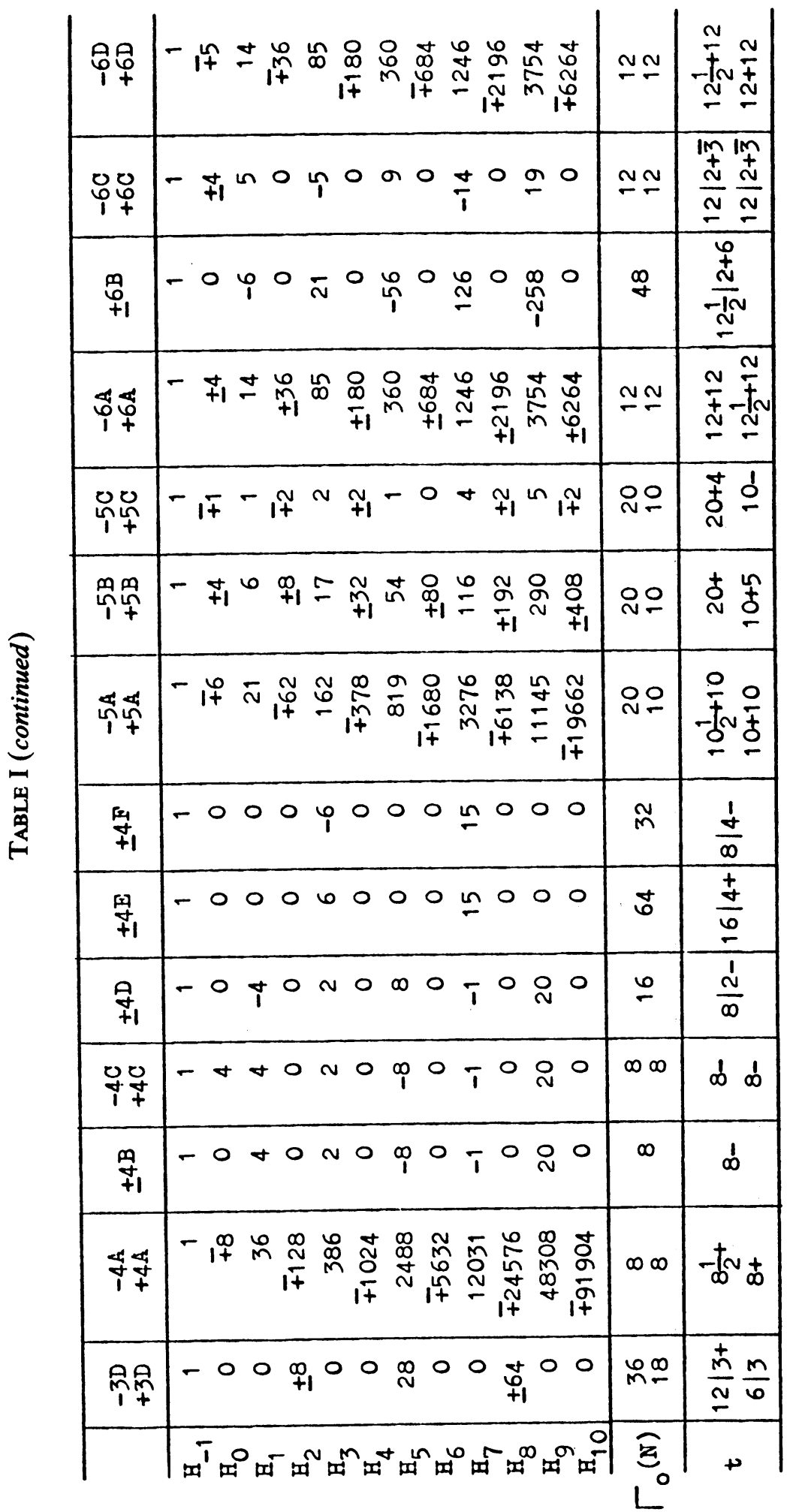




\begin{tabular}{|c|c|c|c|}
\hline ตू' & $-00_{\text {If }} 00-00 \frac{1}{+1} 00$ & 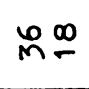 & $\underset{m}{\stackrel{+}{+}} \stackrel{\dot{1}}{\infty}$ \\
\hline कீळ్ & 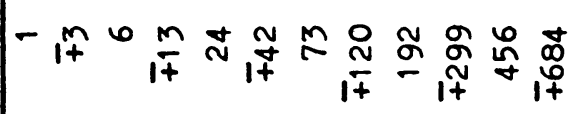 & 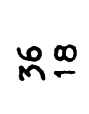 & $\overbrace{\infty}^{\infty} \frac{\infty}{\Phi}$ \\
\hline$\stackrel{\substack{1 \\
\infty \\
+1}}{+1}$ & 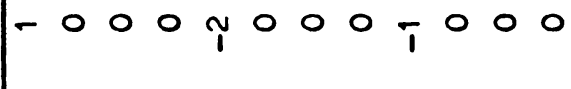 & H & -10 \\
\hline 固罩 & -17000000001000 & $\dddot{6}$ & $\stackrel{1}{b}$ \\
\hline$\stackrel{9}{\phi_{+1}}$ & $-0000 N 0001000$ & $\dddot{0}$ & $\underline{b}$ \\
\hline ర్ల్ర & 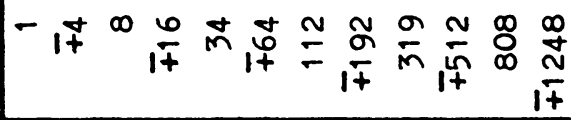 & $\because 0$ & 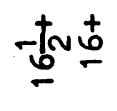 \\
\hline$\stackrel{\substack{\infty \\
+\neq \\
+1}}{9}$ & 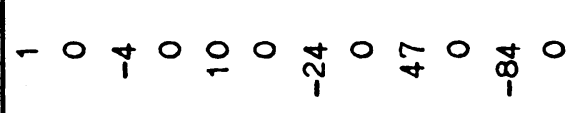 & $\tilde{m}$ & $\frac{ \pm}{-j w}$ \\
\hline 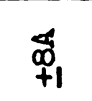 & 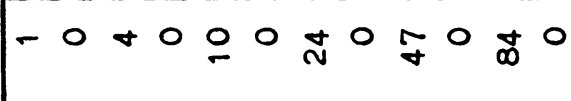 & $\tilde{m}$ & $\frac{t}{6}$ \\
\hline$\underset{1}{9} \underset{+}{q}$ & 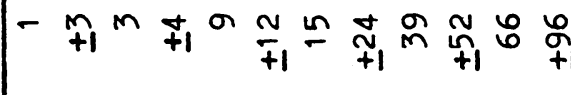 & $\stackrel{\infty}{\sim} \leftleftarrows$ & 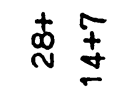 \\
\hline 좀 & - It & $\stackrel{\infty}{\sim} \pm$ & $\frac{d}{\pi \frac{\pi}{d}}$ \\
\hline $\begin{array}{l}-1 \\
0 \\
+1\end{array}$ & - -000000400000 & $\cong$ & $\frac{6}{\cong}$ \\
\hline$\stackrel{\text { 鼻 }}{+1}$ & -00000000000 & $\Xi$ & $\frac{d^{2}}{f^{\prime}}$ \\
\hline$\underset{+1}{+\infty}$ & 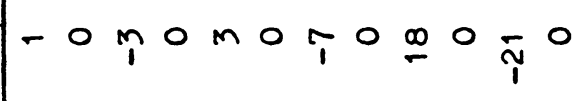 & $\stackrel{\Delta}{\sim}$ & $\stackrel{+}{\stackrel{+}{N}}$ \\
\hline $\begin{array}{l}y_{4} y_{1} \\
1+\end{array}$ & 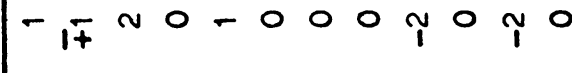 & $\simeq \cong$ & $\stackrel{1}{\stackrel{1}{\sim}}$ \\
\hline 里里 & $-i+T 0 \sim 0$ T $000 \underset{\sim}{m} 0$ & $\simeq \cong$ & $\underset{+}{\stackrel{m}{ \pm}} \stackrel{m}{ \pm}$ \\
\hline & 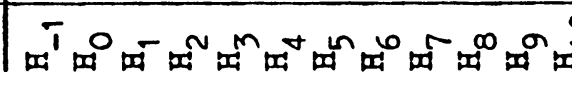 & 互 & D \\
\hline
\end{tabular}




\begin{tabular}{|c|c|c|c|}
\hline 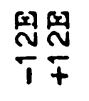 & 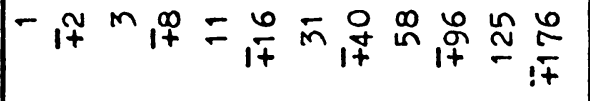 & 出 & $-\underset{N}{-t w}$ \\
\hline$\frac{\text { ลิล }}{1}$ & 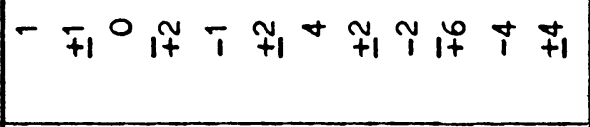 & 芯 & 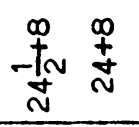 \\
\hline 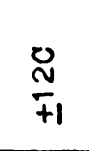 & $-0 n 0 \ln 0$ noj $00 \ldots$ & $\stackrel{\infty}{\forall}$ & $\frac{\stackrel{N}{ \pm}}{\stackrel{+}{d}}$ \\
\hline$\stackrel{\stackrel{m}{2}}{\frac{+}{+1}}$ & $-0 \underset{1}{-} 0$ in $0 \mathbb{1}_{1}^{\infty} 0 \pm 0 \underset{N}{N} 0$ & $\stackrel{\Delta}{N}$ & $\frac{N}{\frac{N}{N} \frac{N}{t}}$ \\
\hline$\frac{\mathbb{N}}{\mathfrak{T}} \frac{1}{+}$ & - & W & \\
\hline$\frac{4}{1}$ & 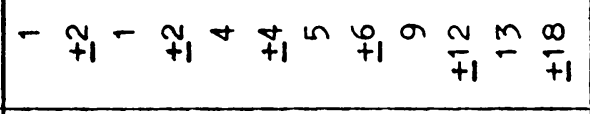 & $\forall \mathbb{N}$ & 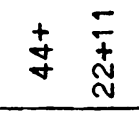 \\
\hline$\frac{\text { 里 }}{\mathrm{T}}$ & $-0 T_{0}^{1}-0 N_{0}-0 \varphi_{0}$ & 웅 & $\frac{\stackrel{L}{+}}{\stackrel{N}{o}}$ \\
\hline$\frac{\text { 엉엉 }}{1}$ & 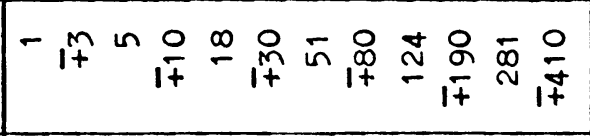 & 유 & 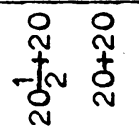 \\
\hline$\frac{8}{1} \frac{8}{+}$ & $-\underset{T}{\pi} 00 m 0$ i & 암ㅇ & 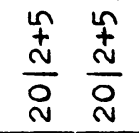 \\
\hline$\frac{8}{+1}$ & $-0 n 0-0 n 0+0,00$ & ○ & $\stackrel{\stackrel{t}{ \pm}}{\stackrel{Q}{+}}$ \\
\hline$\stackrel{p}{\circ}$ & - 0 m 0 1 $00 \frac{1}{1} 0$ n $0 \prod_{1} 0$ & ০ & $\frac{\substack{ \pm \stackrel{N}{N}}}{-\underset{N}{N}}$ \\
\hline 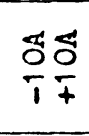 & 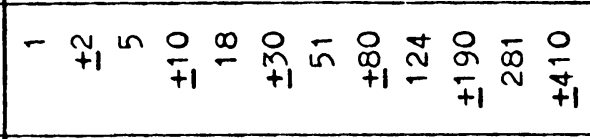 & 유 & 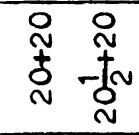 \\
\hline 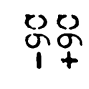 & $-m_{+1}^{m} \underset{+1}{\sim} m \stackrel{0}{\sim} \underset{+1}{\sim} \underset{+1}{\sim} \stackrel{\sim}{m} \underset{+1}{m}$ & $\ddot{m}$ & 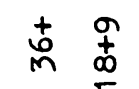 \\
\hline & 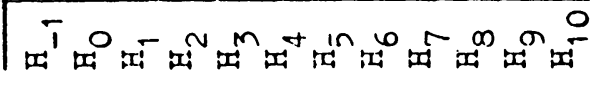 & $\widehat{\underline{3}}$ & + \\
\hline
\end{tabular}




\begin{tabular}{|c|c|c|c|}
\hline $\min _{1}^{\operatorname{mon}}$ & 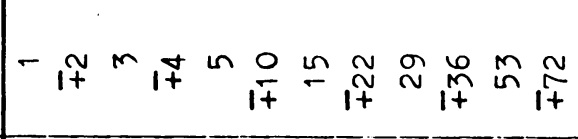 & 응으 & 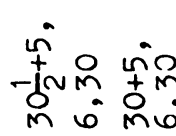 \\
\hline 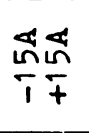 & $-m m m_{11} 0000 m_{11} \sigma q_{+1}^{m} m_{+1}$ & 응으 & 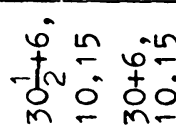 \\
\hline 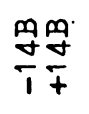 & $-\overline{1}-0-0 T 0 m 0 \% 0$ & $\stackrel{\infty}{\sim} \stackrel{\infty}{\sim}$ & 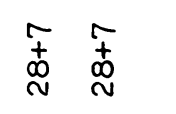 \\
\hline$\frac{4}{+1}$ & - -1 i m & $\cong$ & 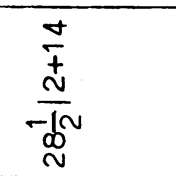 \\
\hline$\stackrel{m}{m} \frac{\pi}{T}$ & 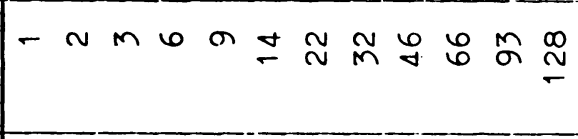 & iñ & 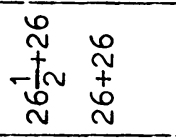 \\
\hline$\frac{\sum}{\stackrel{+}{+}}$ & -00000000000 & $\stackrel{\infty}{\infty}$ & $\frac{\stackrel{1}{\simeq}}{\stackrel{d}{\sim}}$ \\
\hline$\stackrel{\stackrel{a}{N}}{+1}$ & -00000000000 & $\stackrel{0}{i}$ & $\stackrel{\stackrel{+}{\sim}}{\frac{5}{\infty}}$ \\
\hline$\frac{\stackrel{N}{N}}{1} \frac{4}{t}$ & 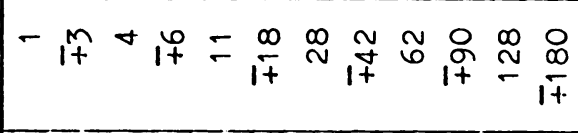 & 芯 & 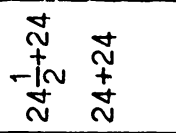 \\
\hline$\stackrel{\stackrel{2}{N}}{+1}$ & - OTOTOT T N & $\stackrel{\infty}{q}$ & $\frac{\stackrel{m}{ \pm}}{\stackrel{d}{d}}$ \\
\hline$\stackrel{H}{\stackrel{H}{N}} \frac{-}{T}$ & $-\frac{1}{n}-0,0-0 N 0 \frac{1}{-1}$ & ָั & $\frac{\stackrel{m}{+}}{\stackrel{m}{\sim}} \stackrel{m}{\stackrel{+}{N}}$ \\
\hline 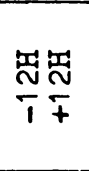 & - if $\underset{1}{N} 0$ in $0 \mathbb{1}_{1} 0 \leq 0 \underset{\sim}{N} 0$ & d & 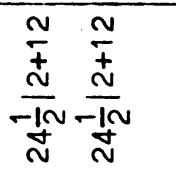 \\
\hline$\stackrel{\stackrel{b}{N}}{+1}$ & $-0-0 T 0-0 n 0^{1} 0$ & $\dot{N}$ & $\frac{m}{\stackrel{m}{N}}$ \\
\hline$\stackrel{\stackrel{\text { fus }}{N}}{+1}$ & $-000 m_{1} 0006000$ & ๙ู & $\frac{\substack{+\underset{-i n}{+}}}{\sim}$ \\
\hline & 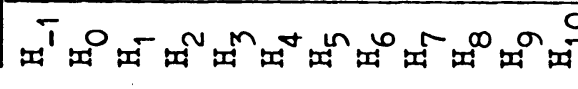 & $\overline{z_{0}}$ & + \\
\hline
\end{tabular}




\begin{tabular}{|c|c|c|c|}
\hline$\frac{m}{\sim} \underset{T}{\sim}$ & 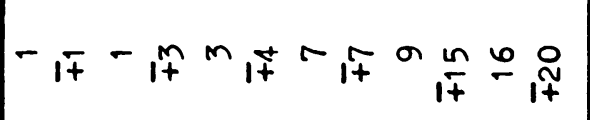 & 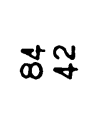 & 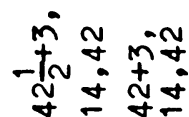 \\
\hline$\stackrel{4}{\underset{1}{N}}$ & 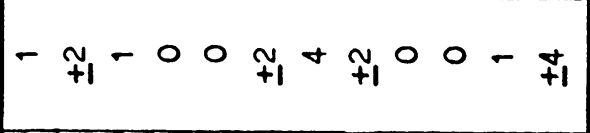 & $\underset{\infty}{*} \stackrel{\sim}{\forall}$ & 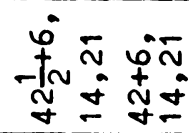 \\
\hline ర্ণ & $-\bar{T}_{1}-0 n 0 m_{0} 000$ in & 암 & 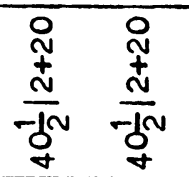 \\
\hline 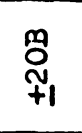 & -00010000000 & $\stackrel{8}{\circ}$ & $\frac{d}{d}$ \\
\hline 유유 & 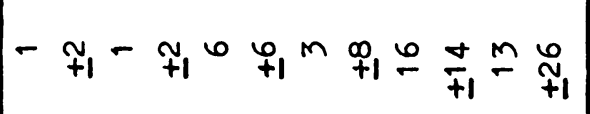 & 앙 & \\
\hline $\begin{array}{l}00 \\
\infty \\
1 \\
1\end{array}$ & $-\mp_{1}-0-000-0 \Psi_{0} 0$ & mำ & $\begin{array}{cc}\frac{a}{t} & \stackrel{a}{+} \\
\frac{w}{w} & \frac{\stackrel{v}{o}}{m}\end{array}$ \\
\hline$\frac{m_{\infty}^{\infty}}{1} \frac{\infty}{\infty}$ & 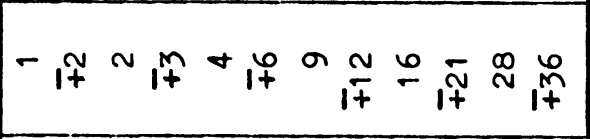 & m̊ำ & $\begin{array}{cc}\stackrel{0}{m} & 0 \\
m & m \\
-j w & 0 \\
m & m\end{array}$ \\
\hline$\frac{\varpi}{1} \frac{0}{\ddagger}$ & 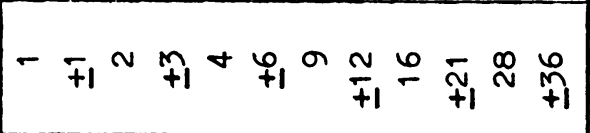 & min & 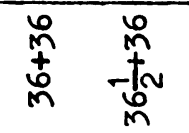 \\
\hline$\frac{m}{6} \frac{m}{6}$ & 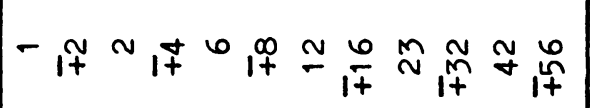 & $\tilde{N} \tilde{N}$ & $\stackrel{-t_{N}}{\stackrel{n}{N}}$ \\
\hline$\frac{\text { है }}{+1}$ & -0 i 0 n 0 itor $0 \frac{1}{0} 0$ & छ & 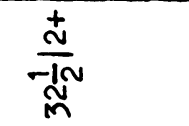 \\
\hline 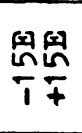 & 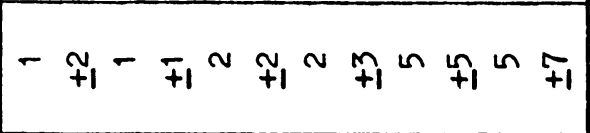 & 응으 & $\stackrel{n}{n}_{m}^{n} \frac{n}{\delta}$ \\
\hline$\frac{\text { ํํํำ }}{1}$ & 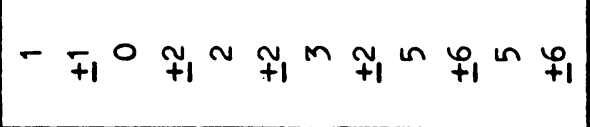 & 요욤 & 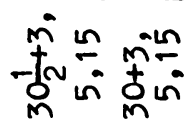 \\
\hline$\frac{0}{1} \frac{0}{T}$ & - 00 it 00 mo 0 it 00 & 용 & $\frac{m}{-j N} \frac{0}{m} \frac{m}{0} \frac{0}{m}$ \\
\hline & 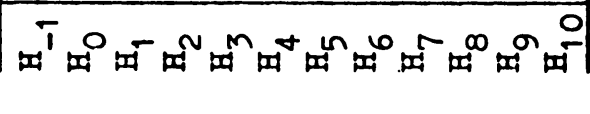 & $\bar{z}_{0}$ & \\
\hline
\end{tabular}




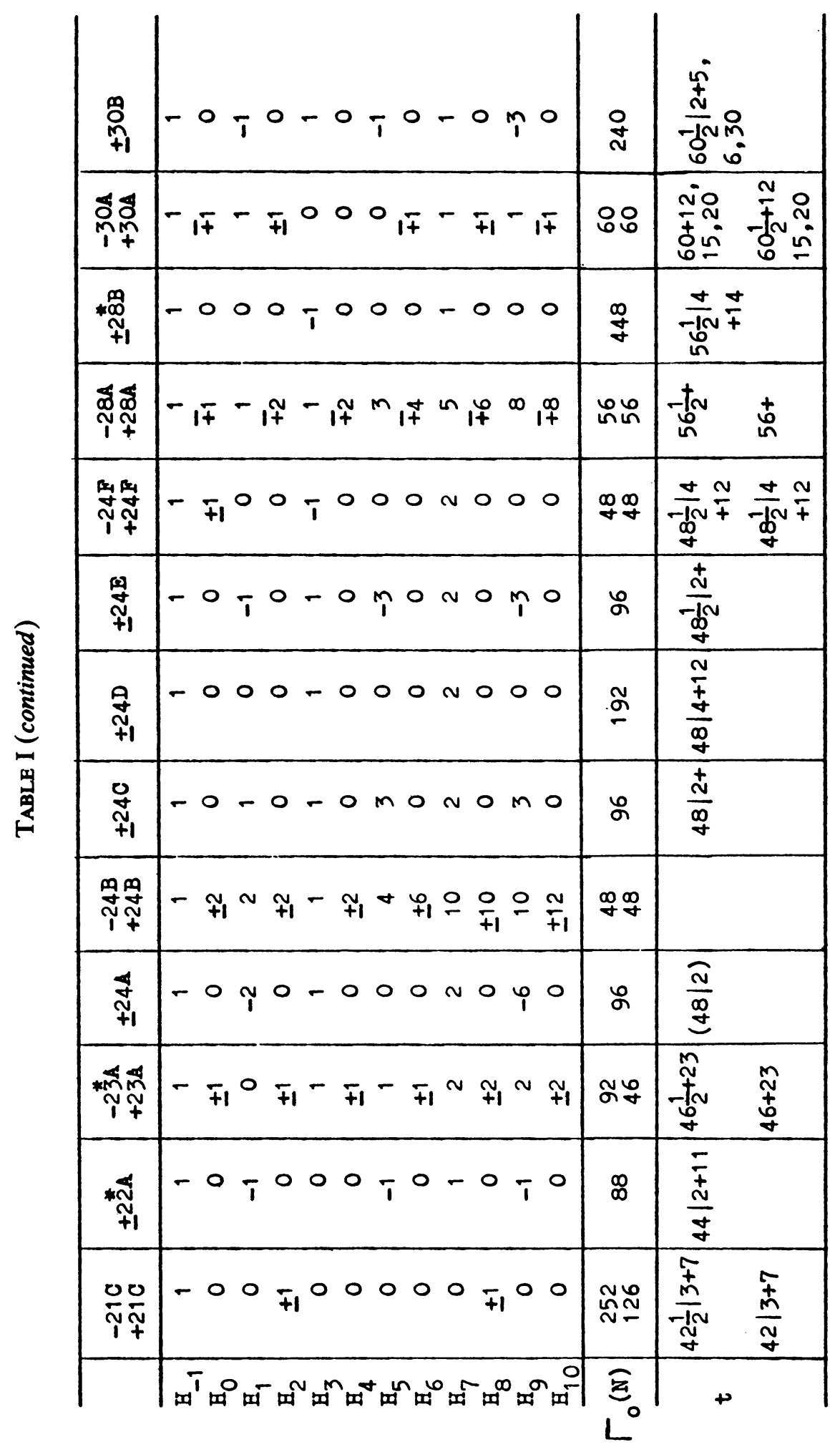




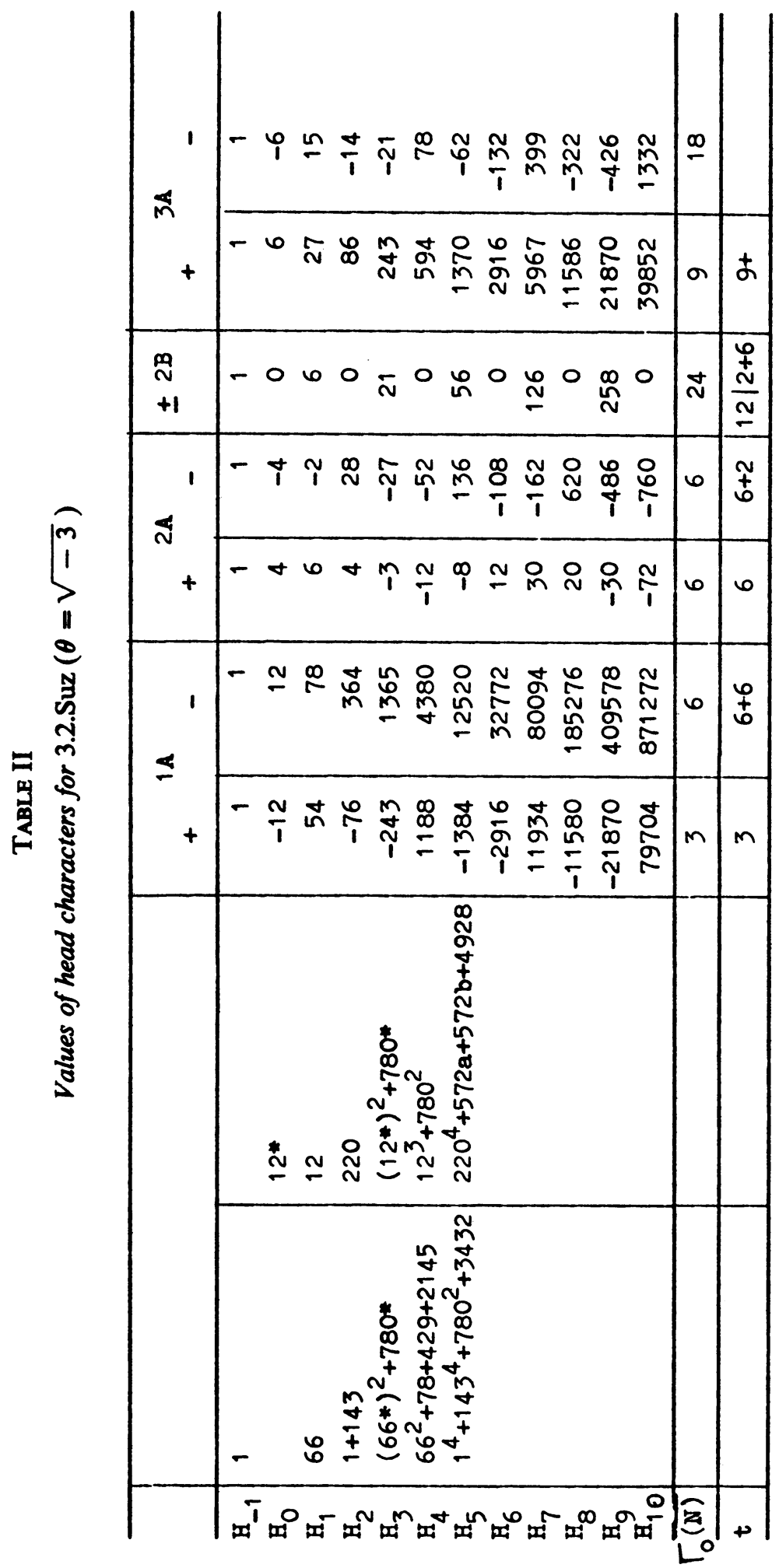




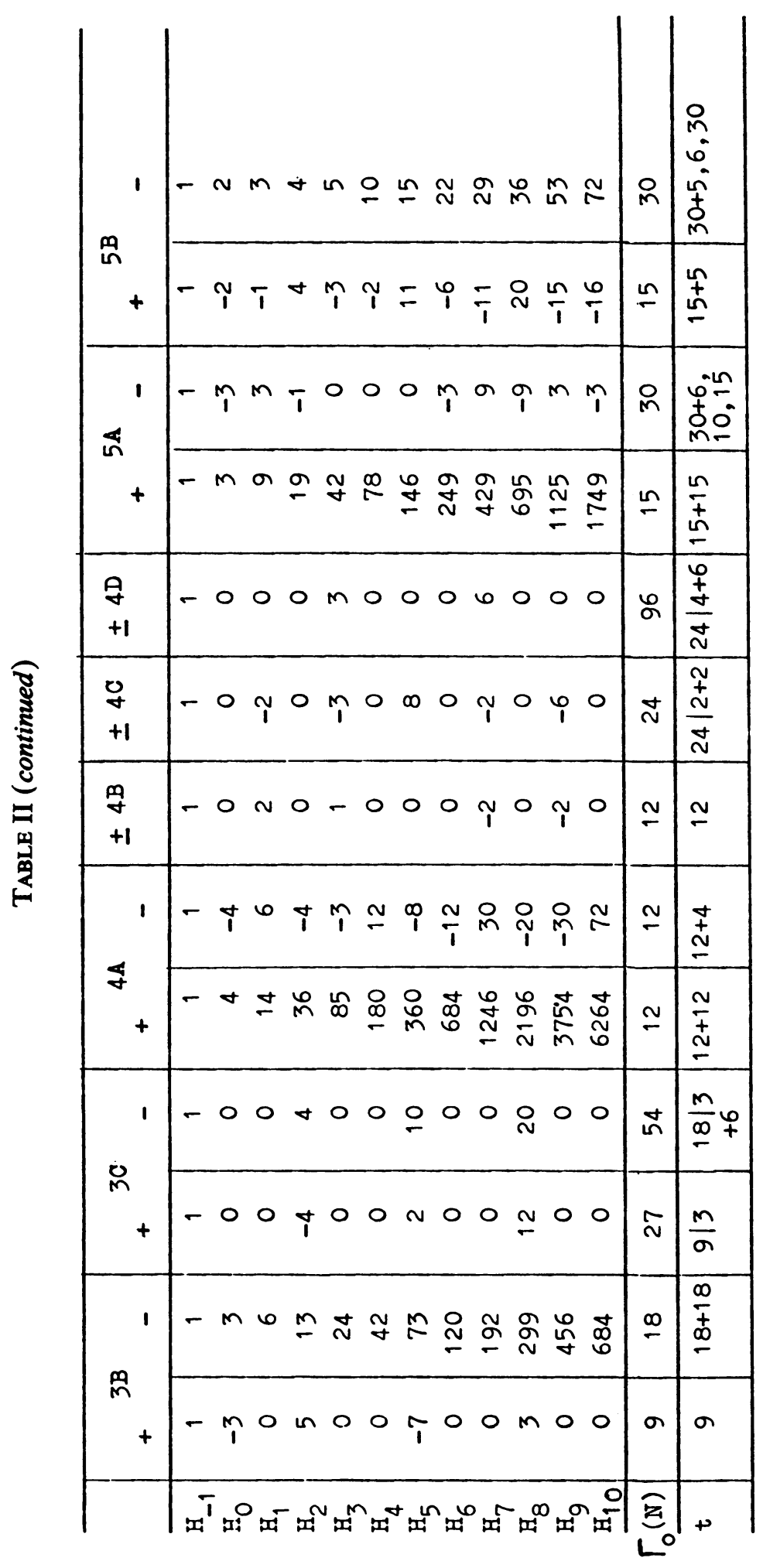




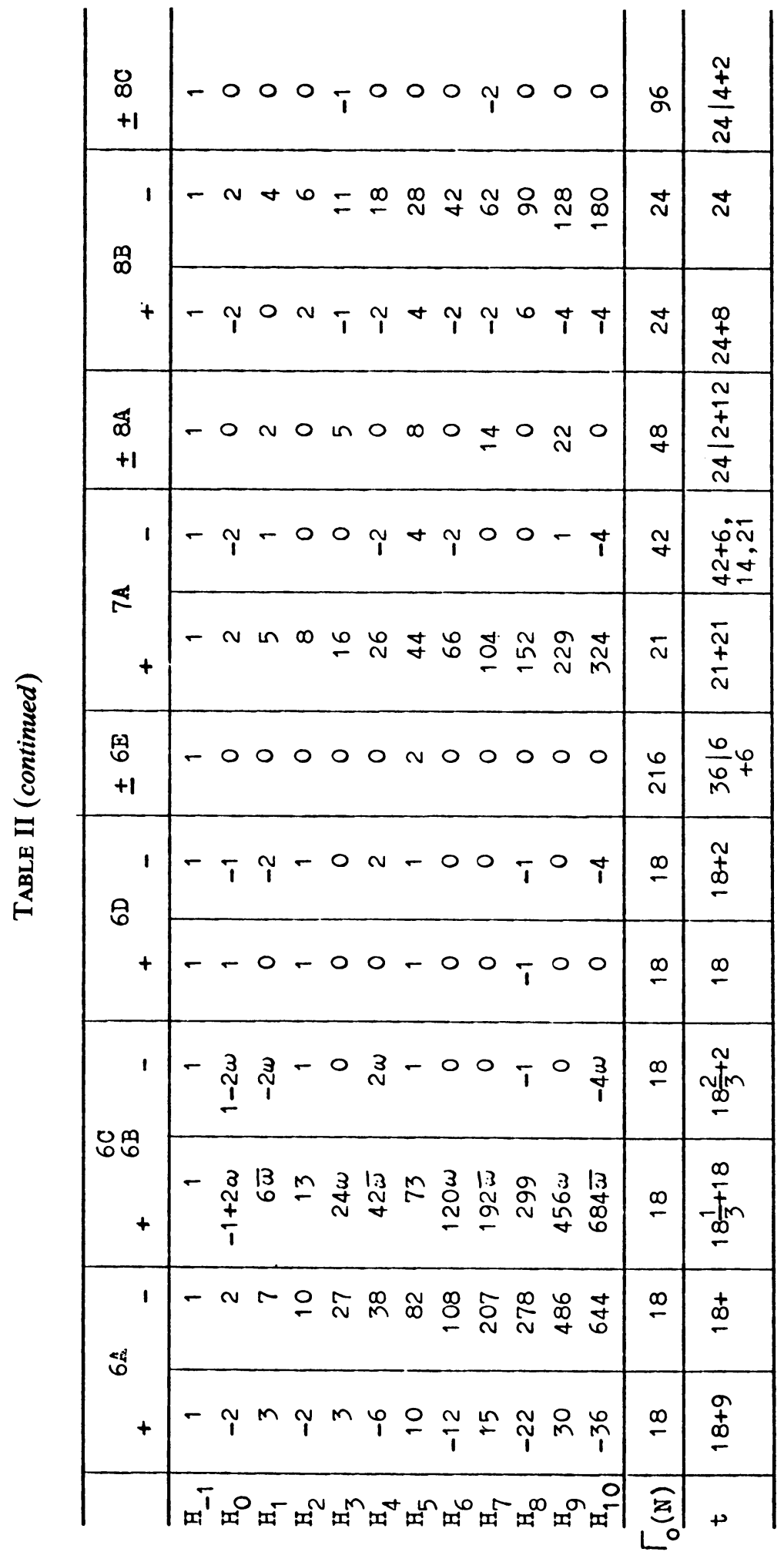




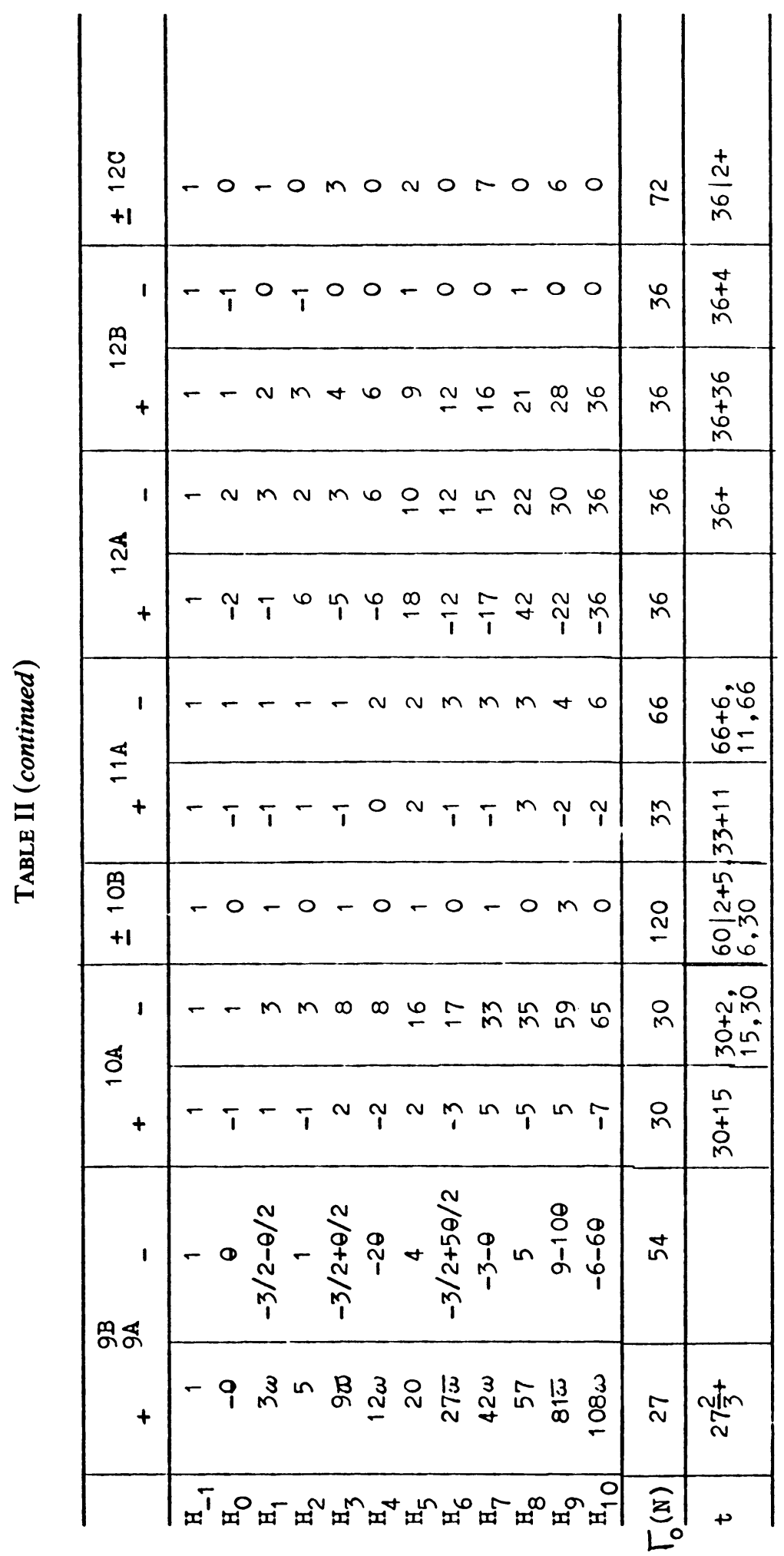




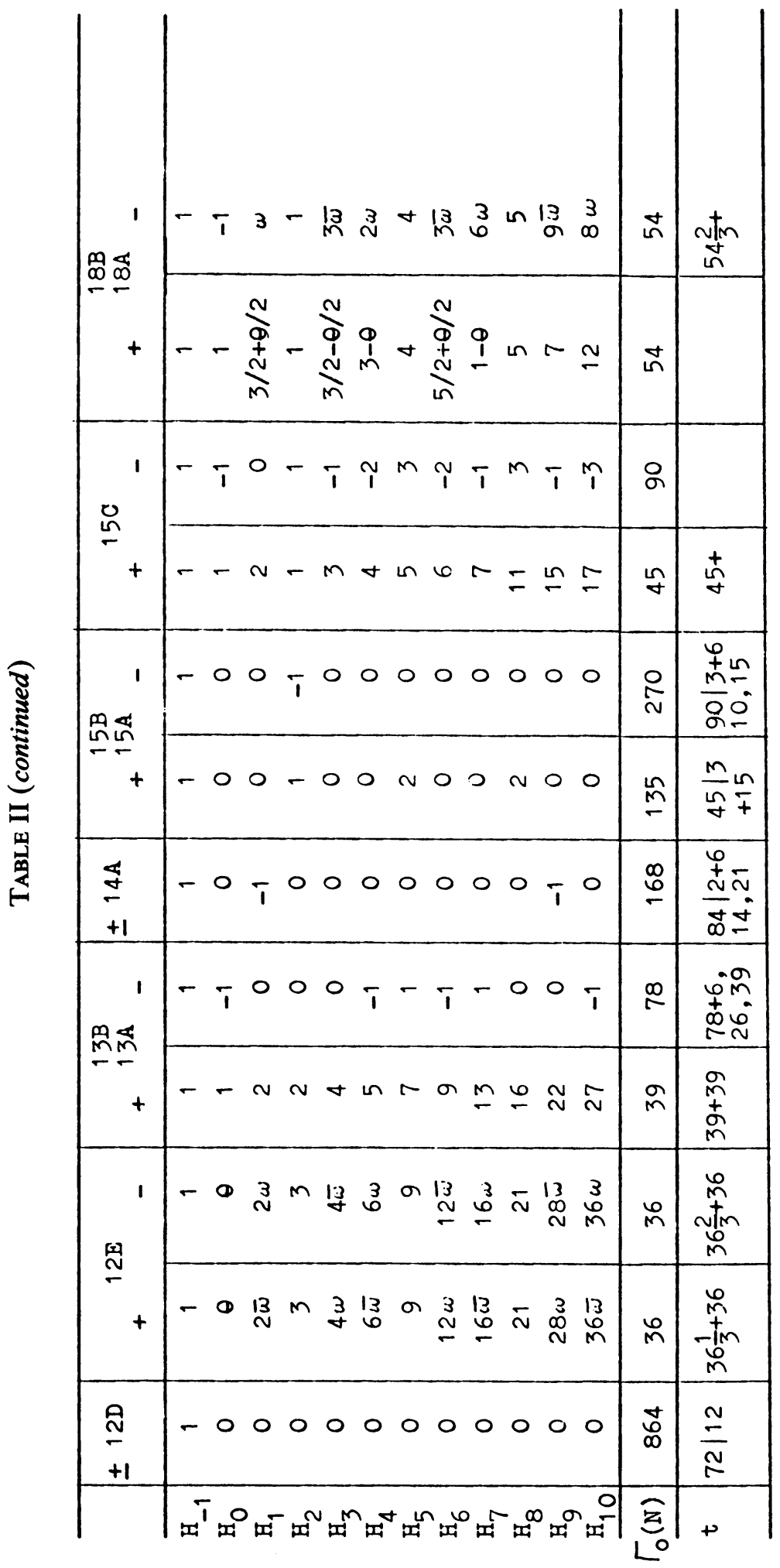




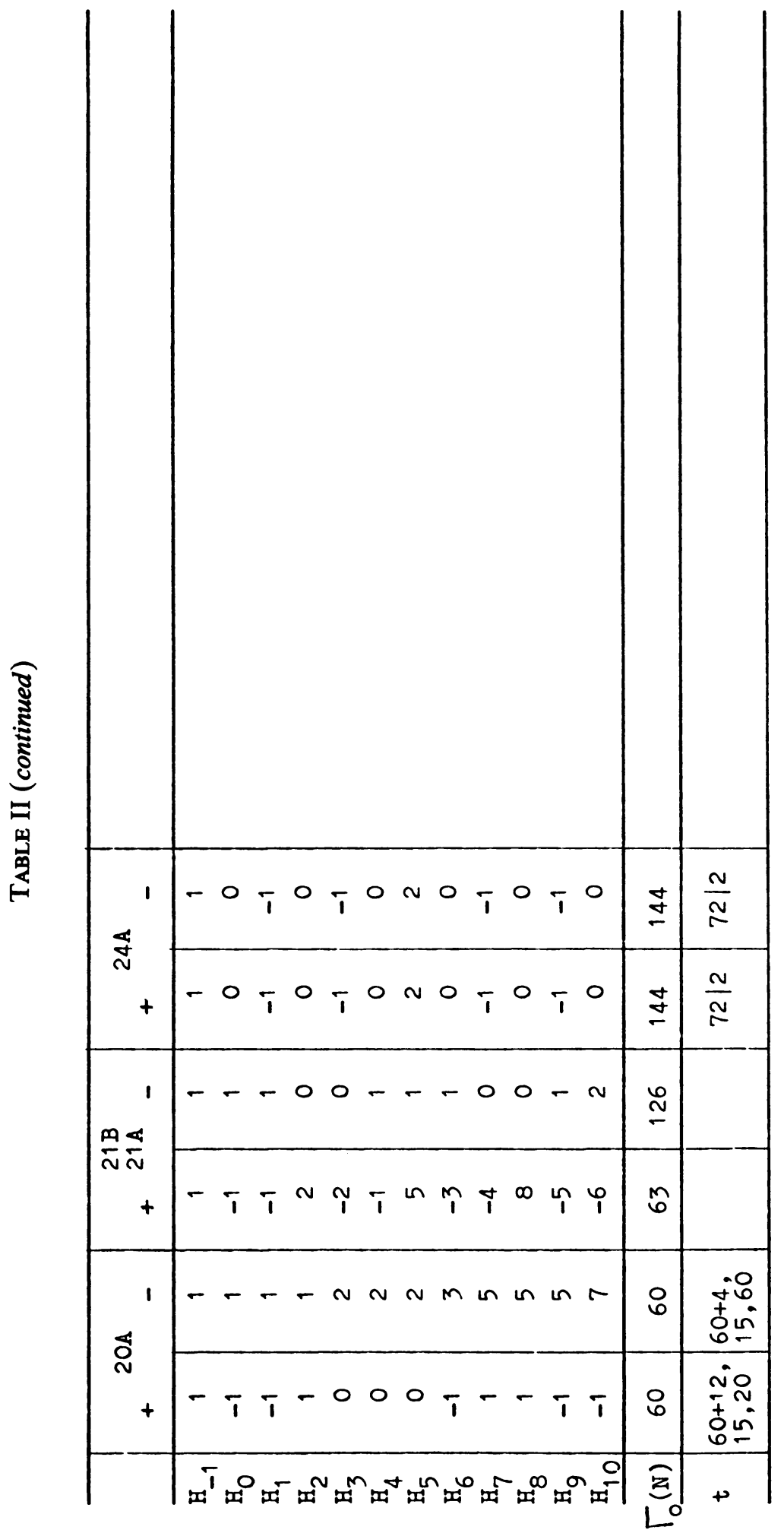




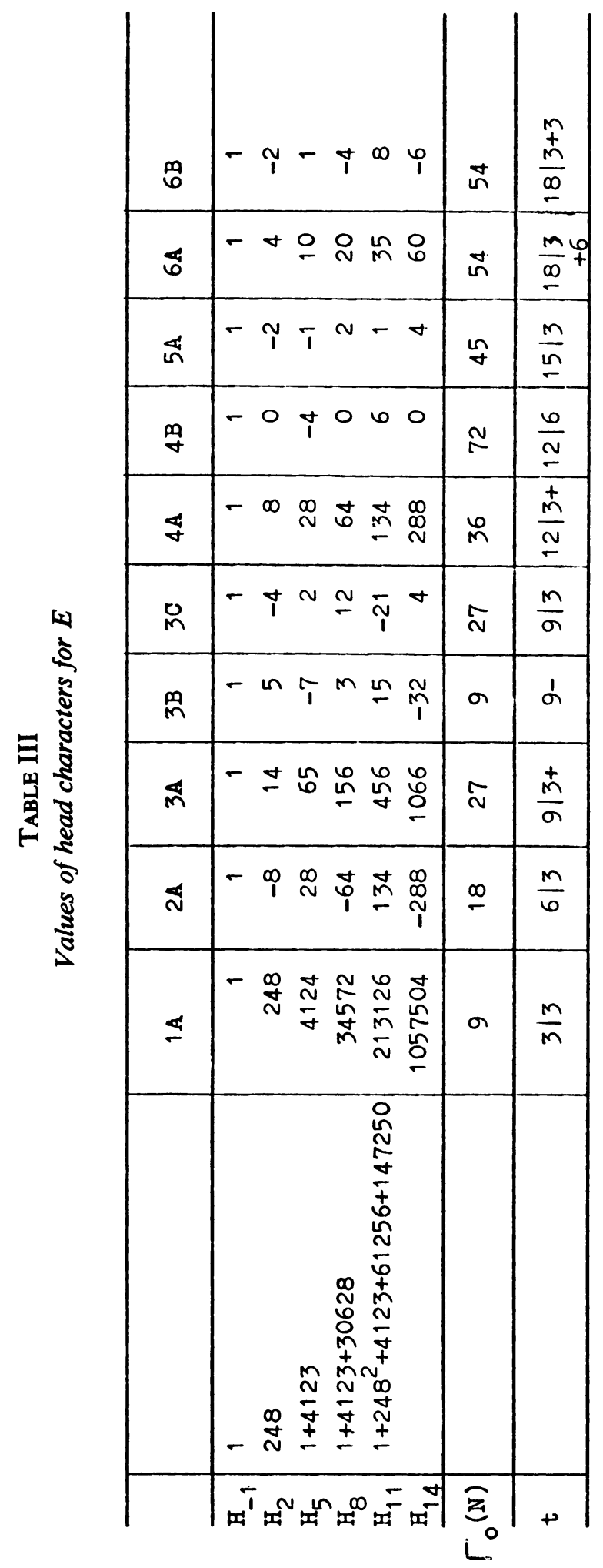




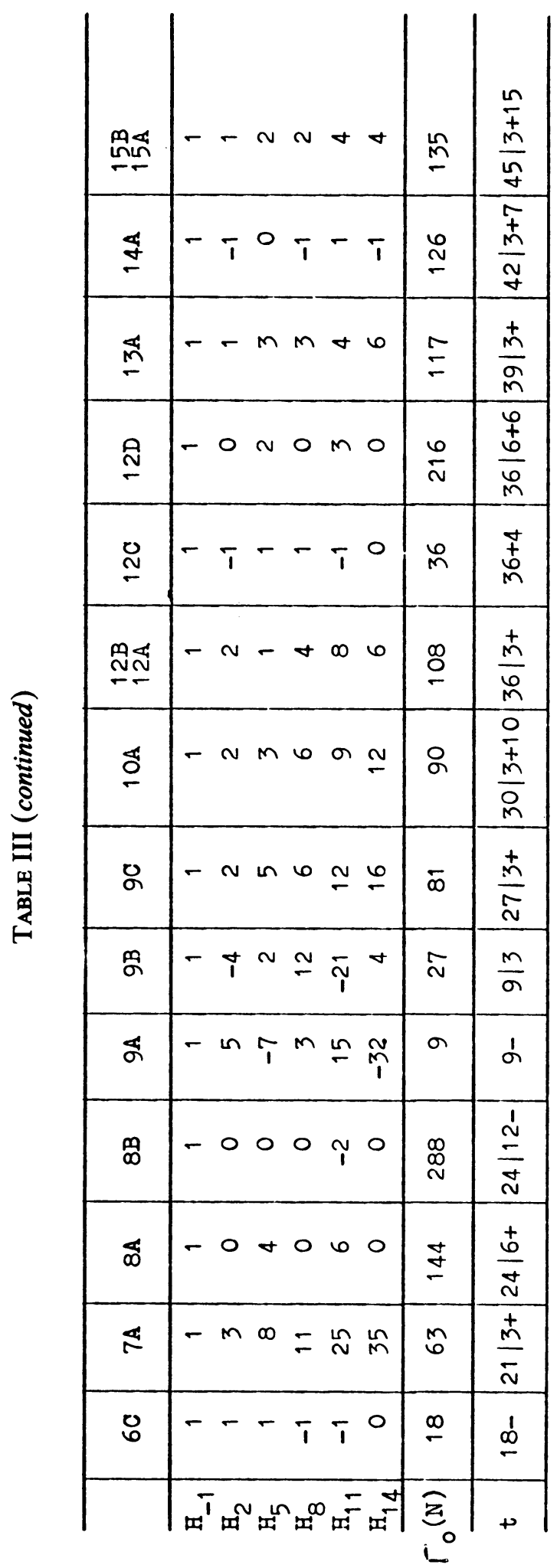




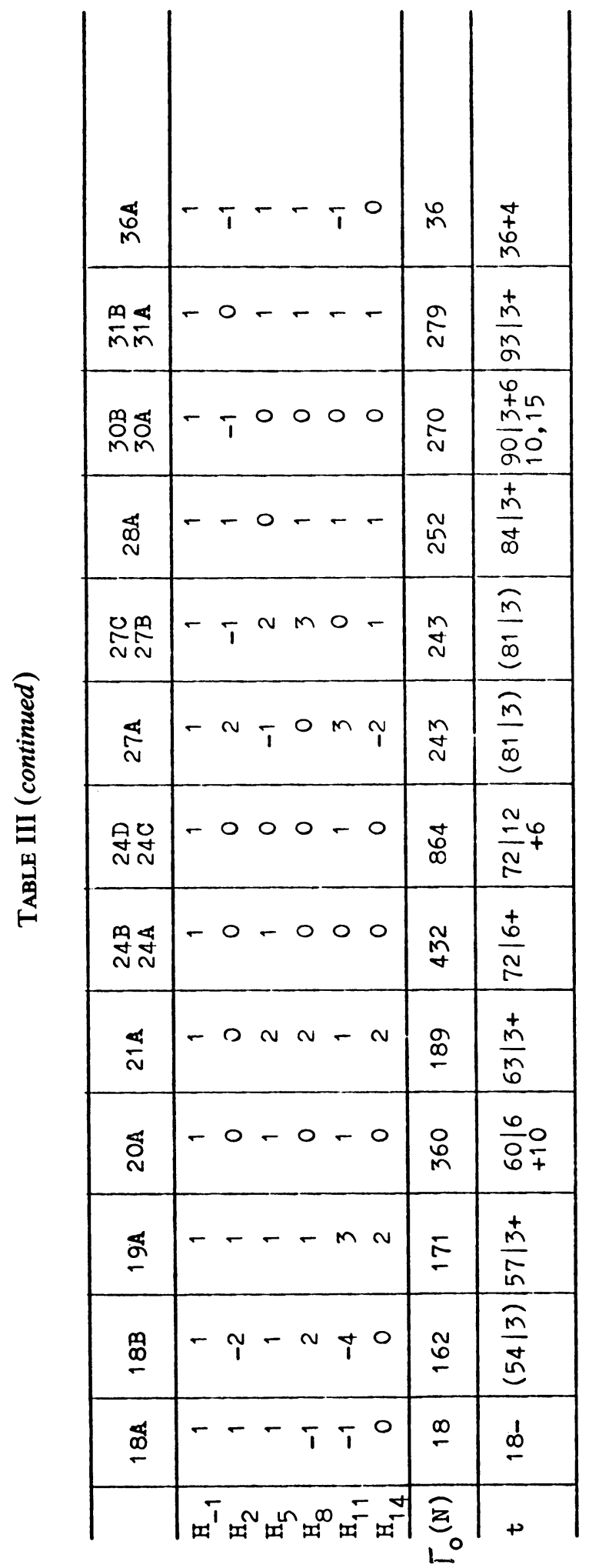




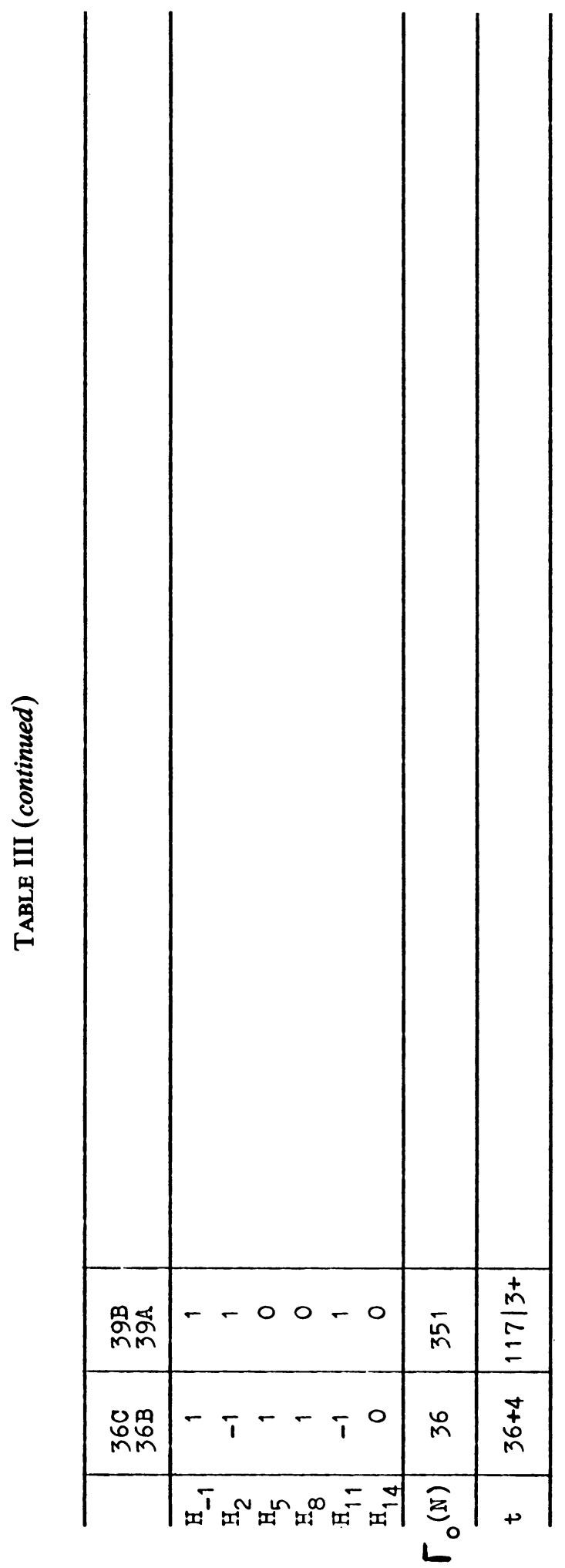




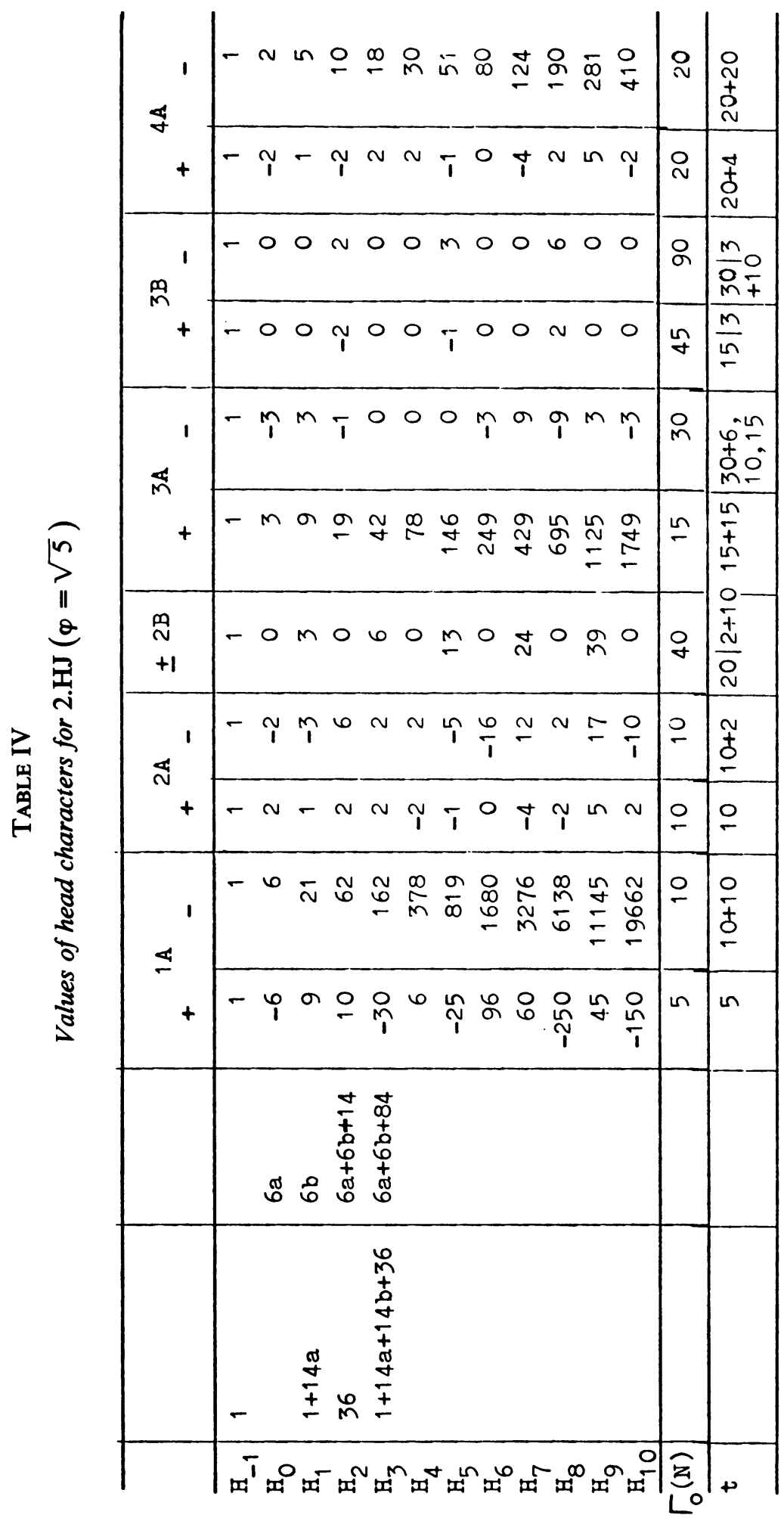




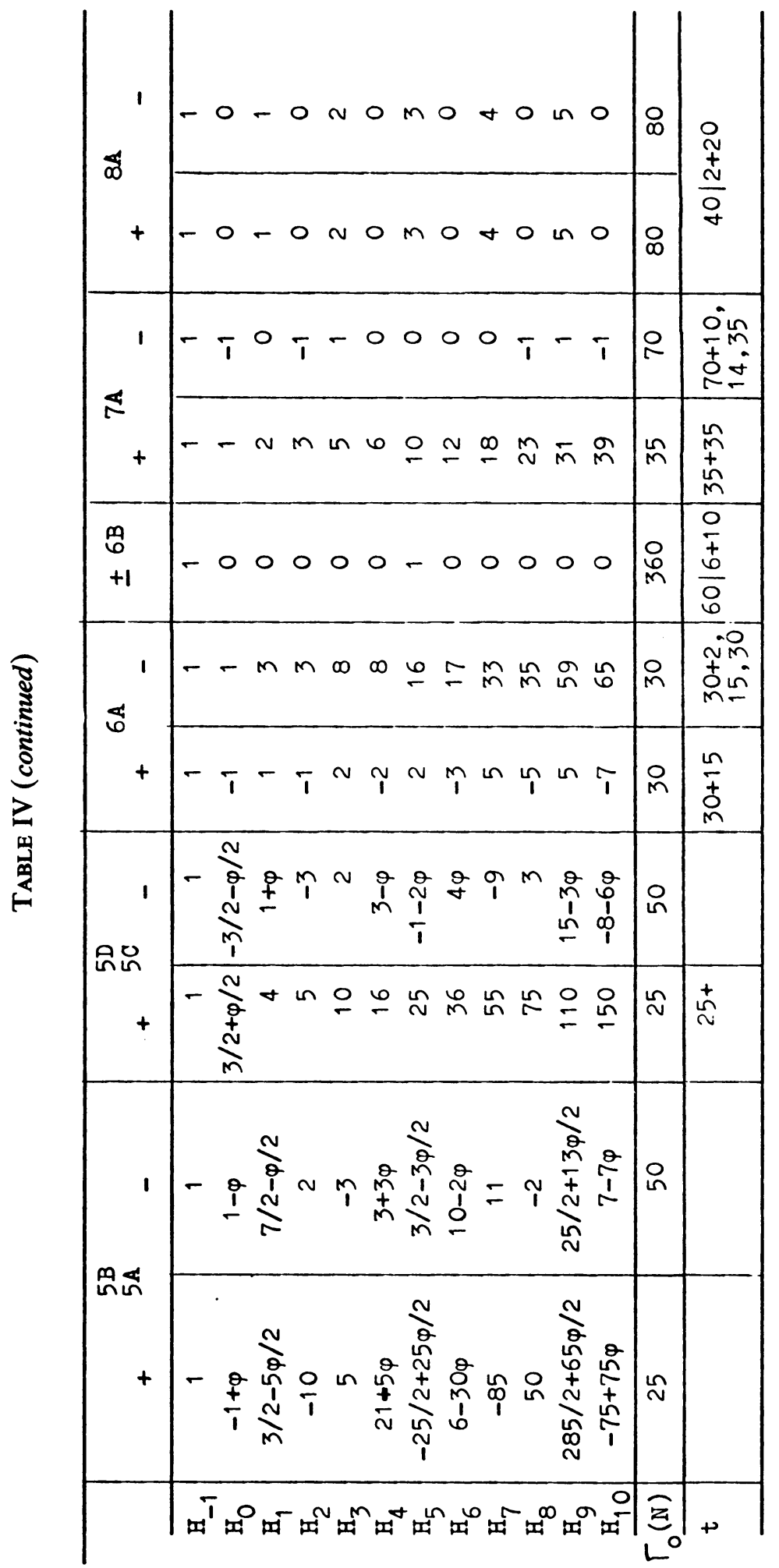




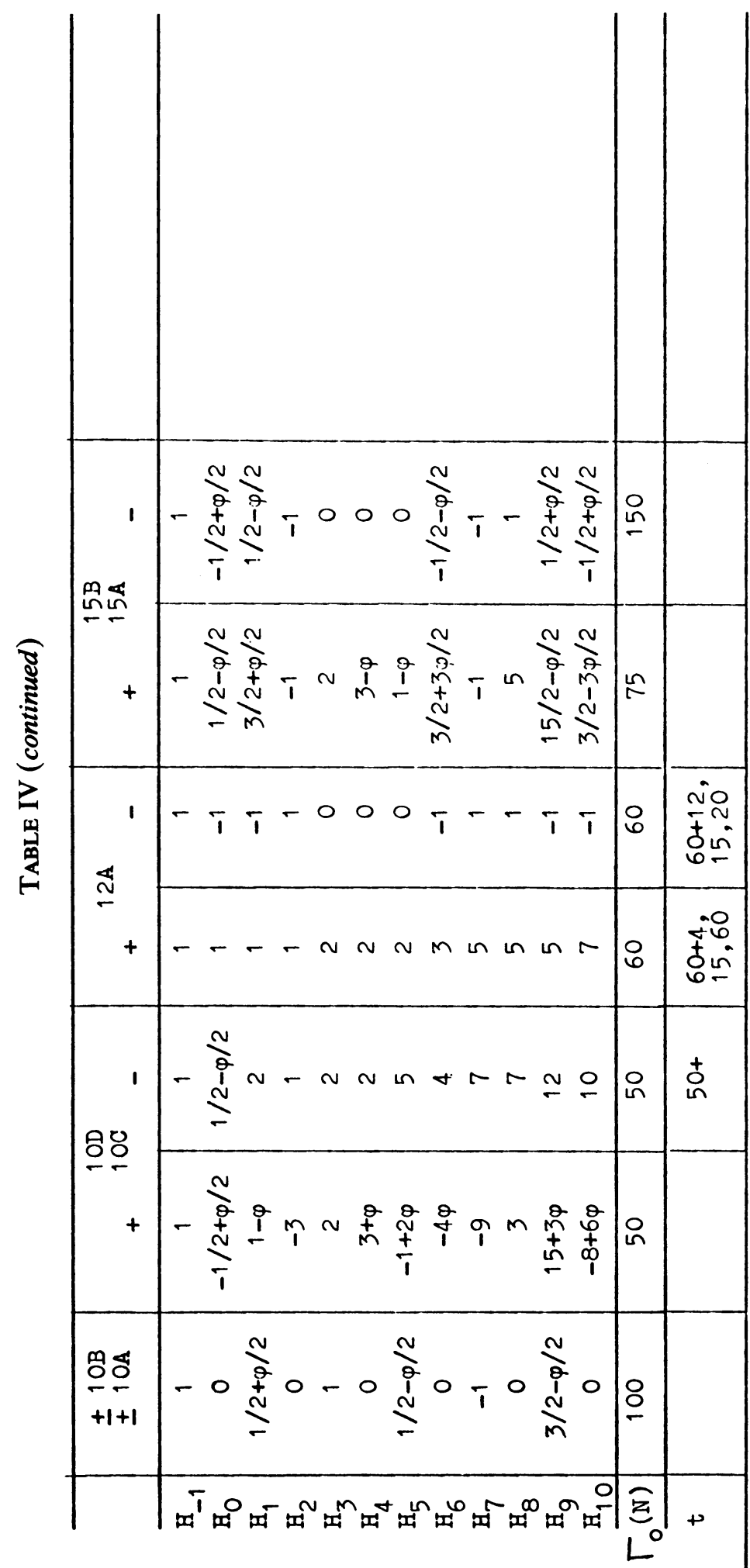




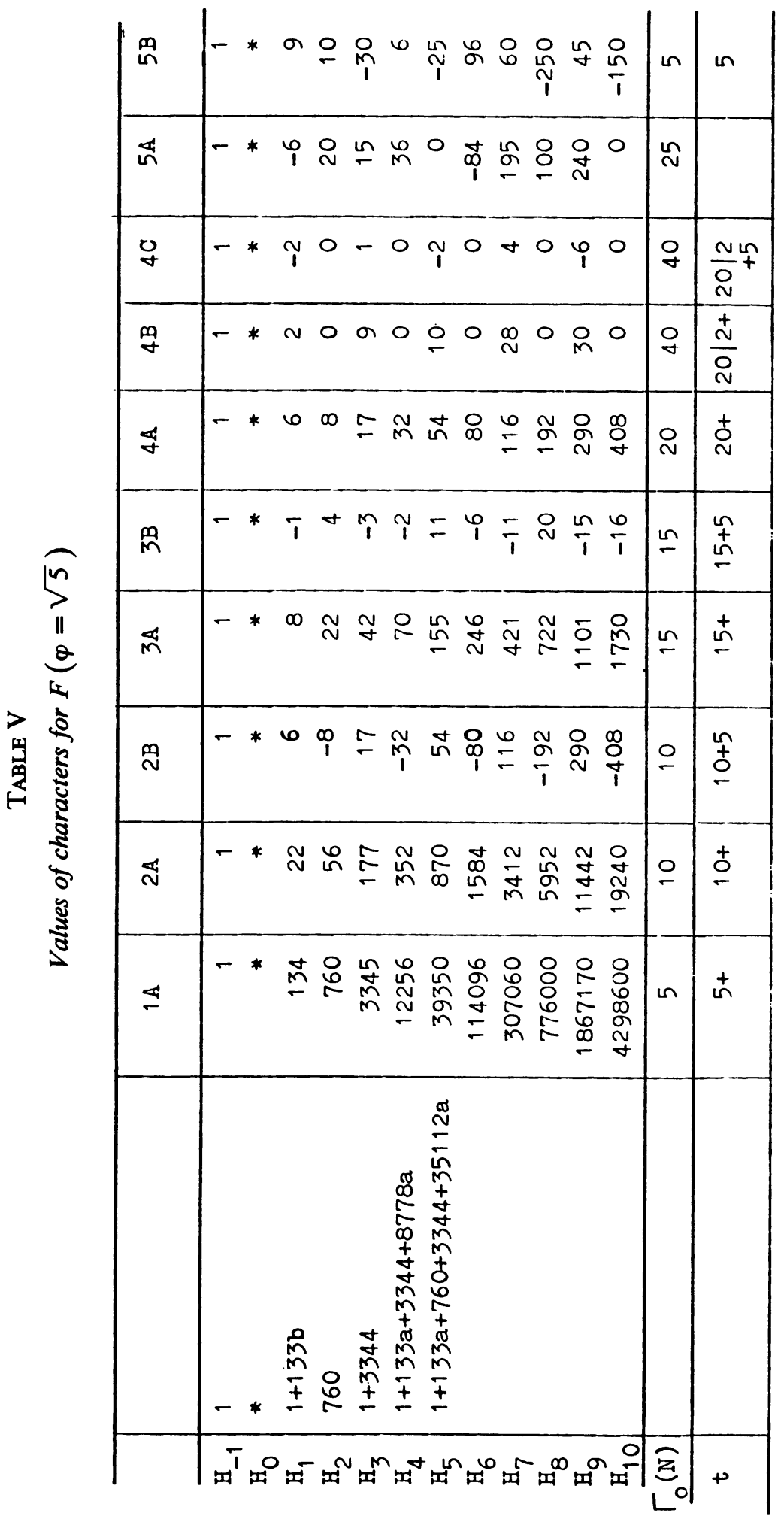




\begin{tabular}{|c|c|c|c|}
\hline 똥응 & 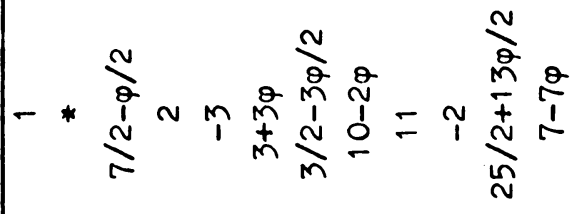 & 온 & \\
\hline$\stackrel{0}{-}$ & $-\pi-n n T^{1} 0 T_{T}^{1} \ln n$ & $\stackrel{0}{-}$ & $\because$ \\
\hline$\underline{\mathscr{p}}$ & $-* \frac{1}{-} \sim 0+\frac{m}{1} \cong \frac{m}{m} 0$ & 은 & \\
\hline$\stackrel{\leftrightarrow}{\circ}$ & $-* \frac{1}{1} 6 \sim \sim \frac{1}{1} \simeq \approx \simeq \frac{1}{1}$ & $\stackrel{\circ}{-}$ & $\underset{⿱}{\mathfrak{a}}$ \\
\hline જీ & $-* \omega-m+\ln \sigma \sigma \underline{I}$ & $\stackrel{\ln }{q}$ & $\stackrel{+}{\stackrel{+}{q}}$ \\
\hline$\stackrel{m}{\infty}$ & $-\pi n 0-0 n 0+0,00$ & $\infty$ & $\frac{\stackrel{t}{ \pm}}{O}$ \\
\hline దో & $-* 00-000+000$ & $\stackrel{\circ}{\circ}$ & $\stackrel{t}{\stackrel{t}{O}}$ \\
\hline 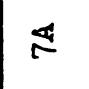 & 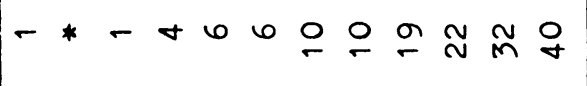 & in & $\stackrel{+}{\mathrm{m}}$ \\
\hline ర్ర & 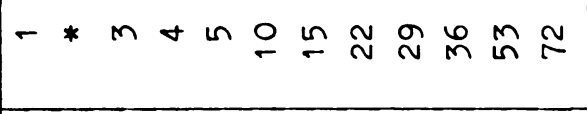 & $\stackrel{\circ}{m}$ & $\begin{array}{l}\text { nio } \\
\text { tom } \\
\text { min }\end{array}$ \\
\hline คి & - & $\stackrel{\circ}{m}$ & min \\
\hline తో & 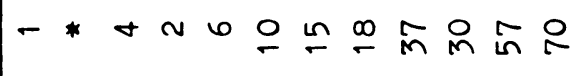 & $\stackrel{\circ}{m}$ & 是 \\
\hline 㖰 & 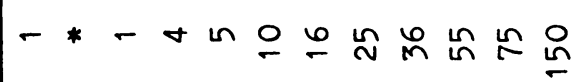 & $\stackrel{\llcorner}{\sim}$ & $\stackrel{+}{\sim}$ \\
\hline 승ำ & 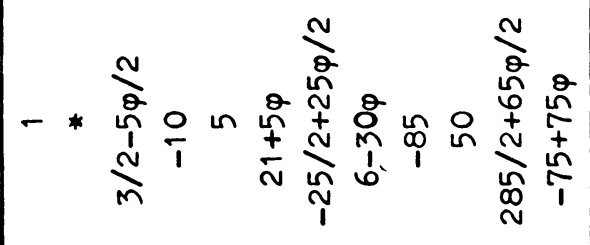 & $\stackrel{n}{\sim}$ & \\
\hline & 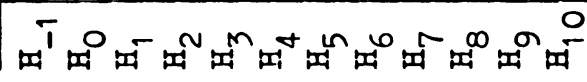 & $\widehat{\underline{z}}$ & + \\
\hline
\end{tabular}




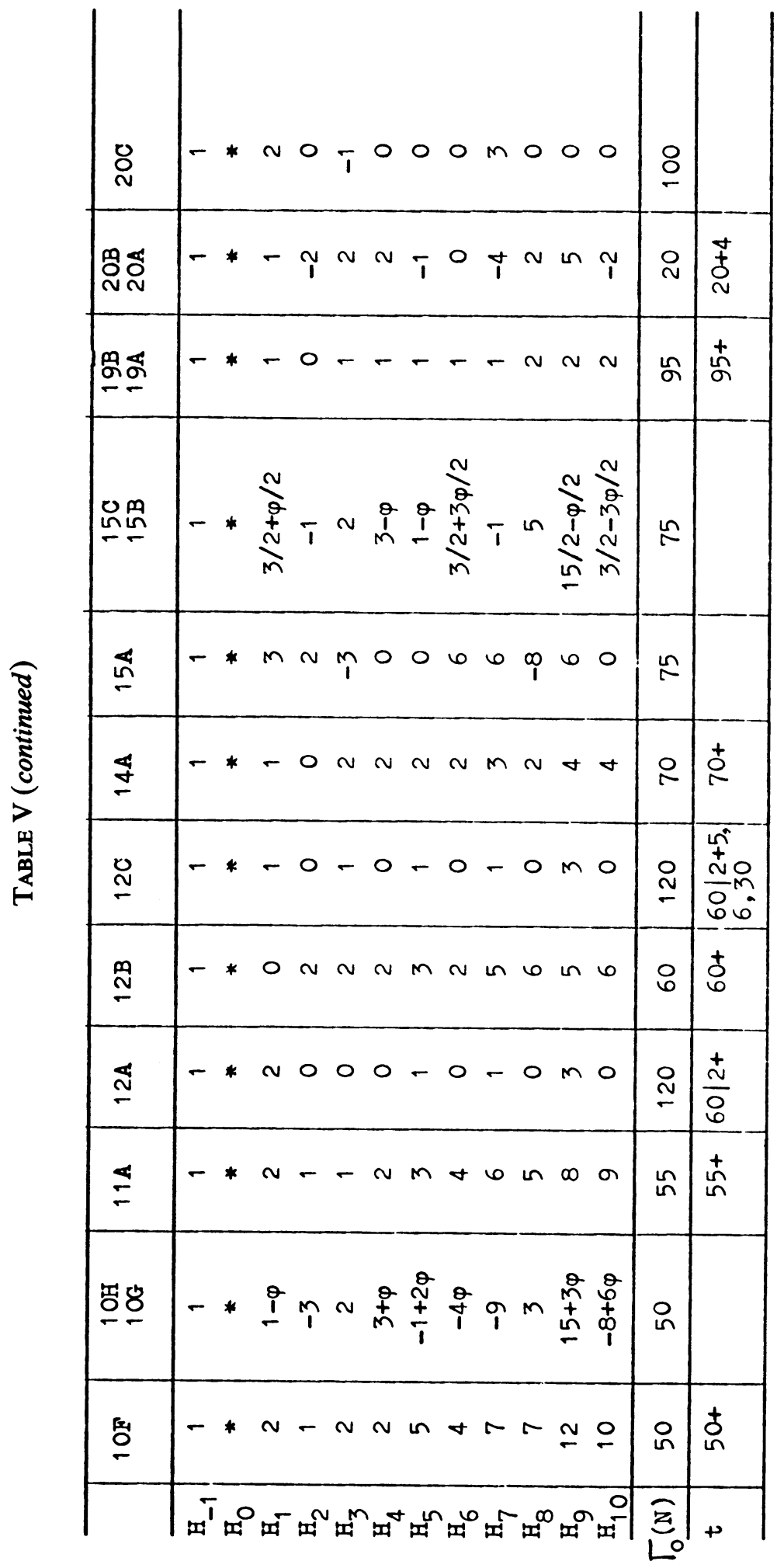




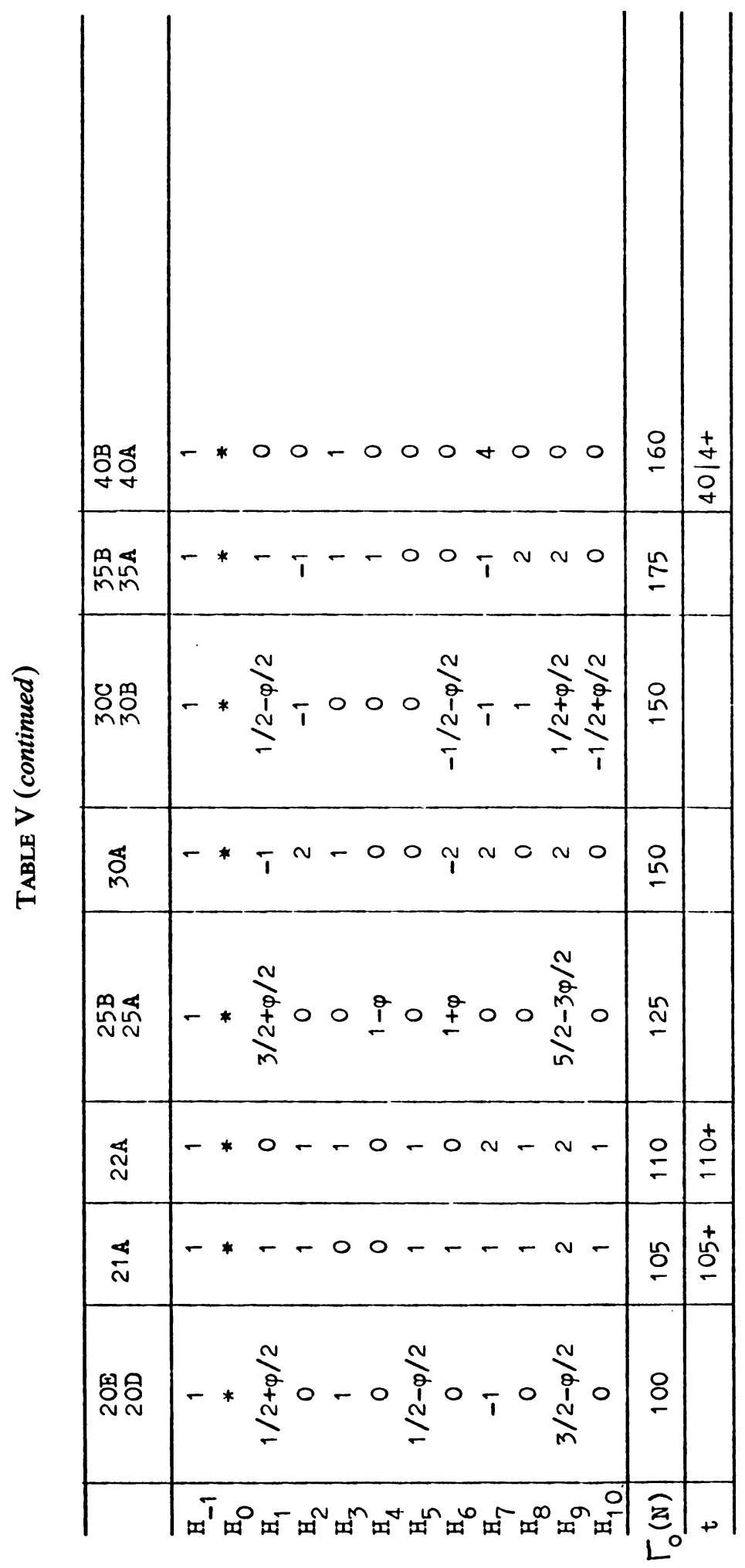




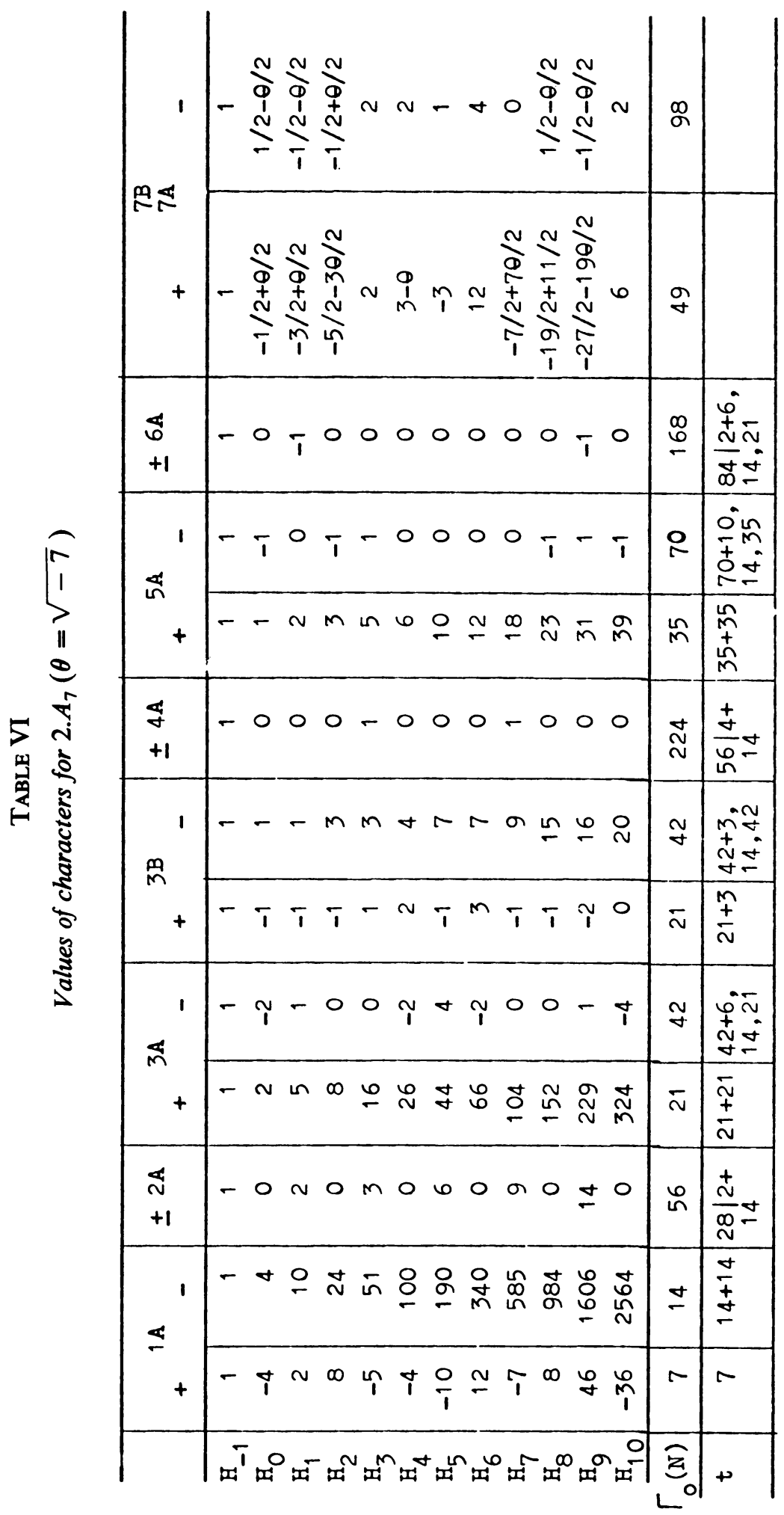




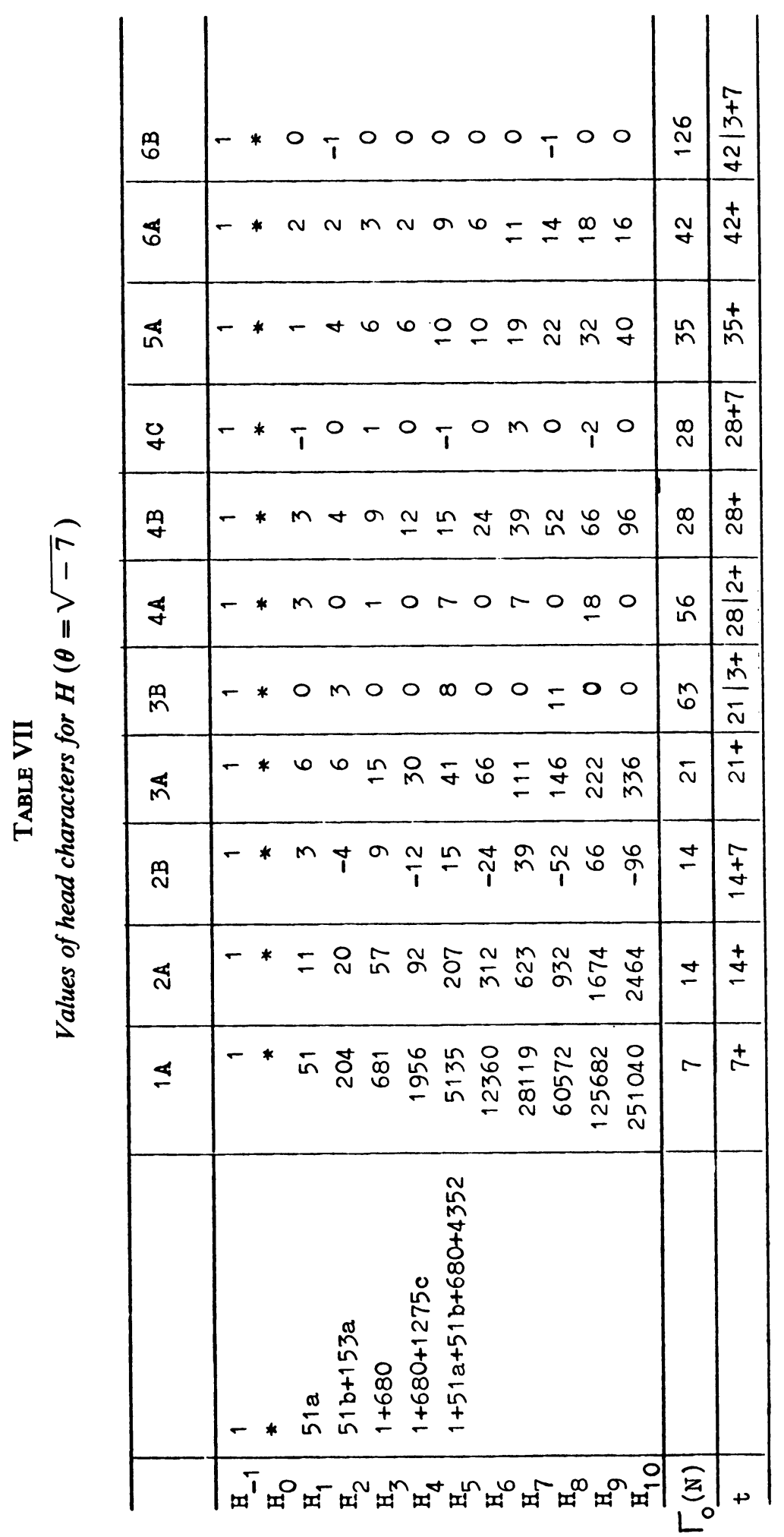




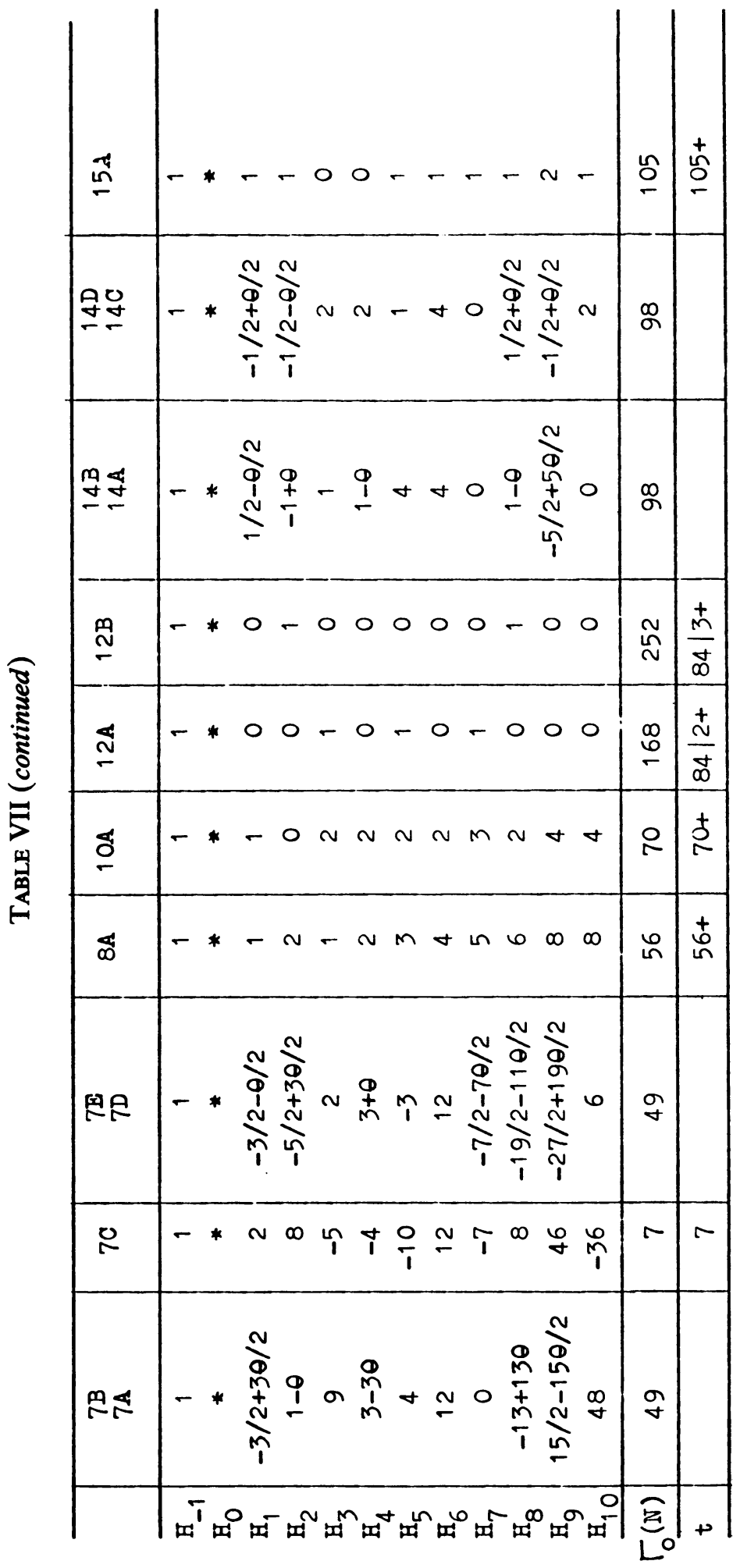




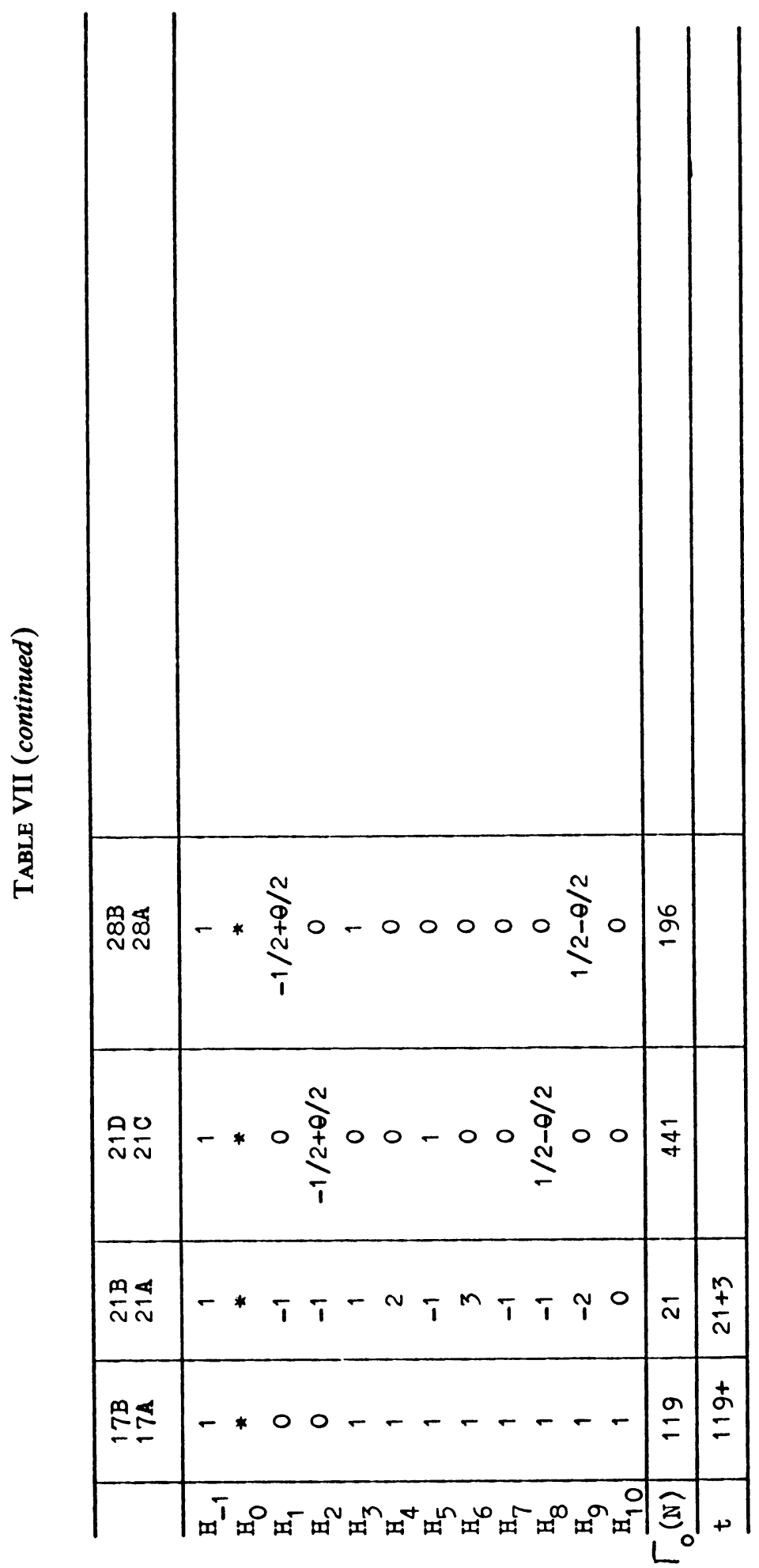




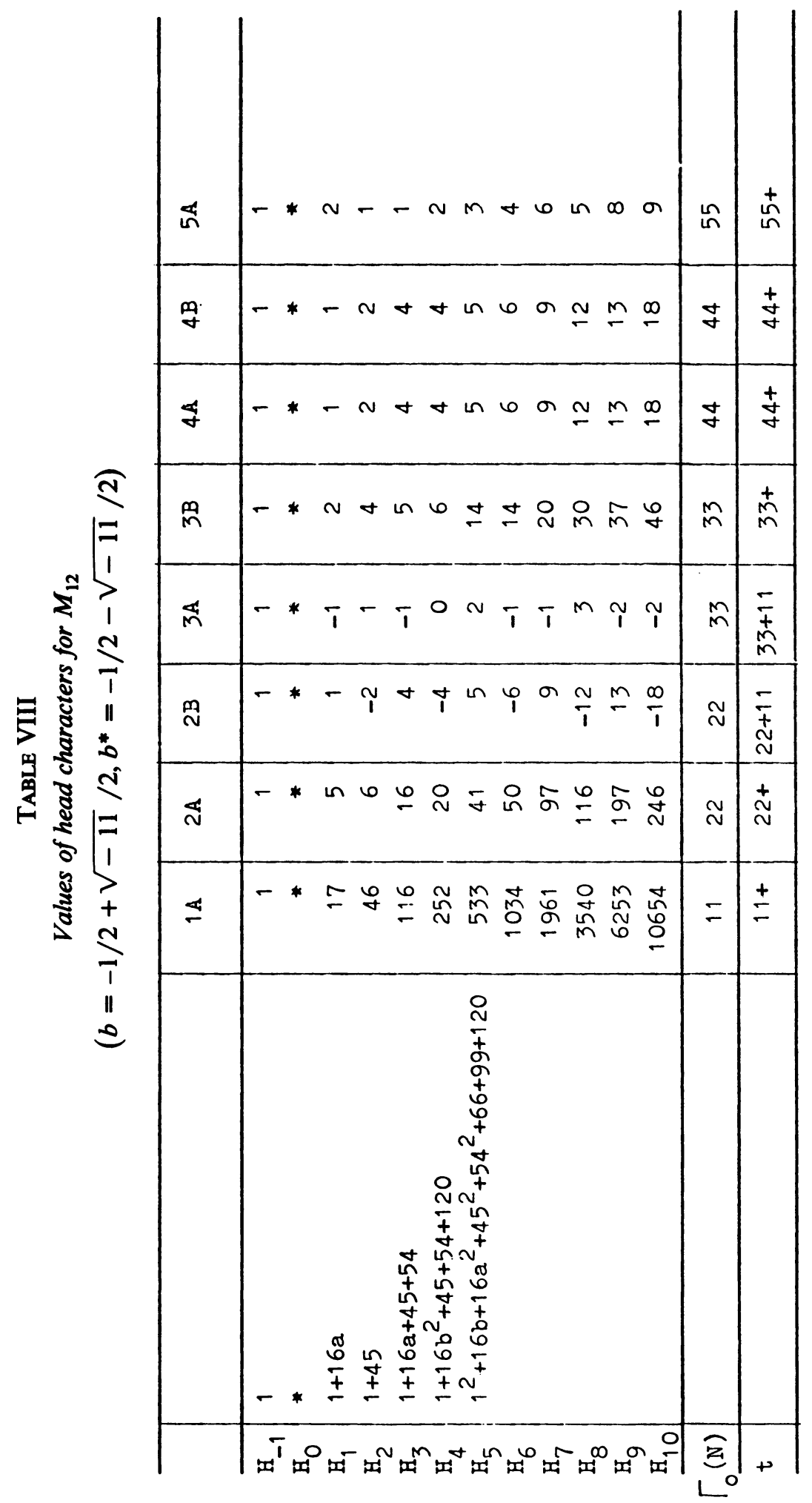

